\title{
Influence of porosity on mechanical properties of tetragonal stabilized zirconia
}

Boccaccini, Dino; Frandsen, Henrik Lund; Soprani, Stefano; Cannio, Maria; Klemensø, Trine; Gil, Vanesa; Hendriksen, Peter Vang

Published in:

Journal of the European Ceramic Society

Link to article, DOI:

10.1016/j.jeurceramsoc.2017.09.029

Publication date:

2018

Document Version

Peer reviewed version

Link back to DTU Orbit

Citation (APA):

Boccaccini, D., Frandsen, H. L., Soprani, S., Cannio, M., Klemensø, T., Gil, V., \& Hendriksen, P. V. (2018).

Influence of porosity on mechanical properties of tetragonal stabilized zirconia. Journal of the European Ceramic Society, 38(4), 1720-1735. https://doi.org/10.1016/j.jeurceramsoc.2017.09.029

\section{General rights}

Copyright and moral rights for the publications made accessible in the public portal are retained by the authors and/or other copyright owners and it is a condition of accessing publications that users recognise and abide by the legal requirements associated with these rights.

- Users may download and print one copy of any publication from the public portal for the purpose of private study or research.

- You may not further distribute the material or use it for any profit-making activity or commercial gain

- You may freely distribute the URL identifying the publication in the public portal 


\title{
Influence of porosity on mechanical properties of tetragonal stabilized zirconia
}

Dino N. Boccaccini ${ }^{\mathrm{a},}{ }^{,}$, Henrik Lund Frandsen ${ }^{\mathrm{a}}$, S. Soprani ${ }^{\mathrm{a}}$, Maria Cannio ${ }^{\mathrm{b}}$, Trine Klemens $\varnothing^{\mathrm{a}}$, Vanesa Gila ${ }^{\mathrm{a}}$, Peter Vang Hendriksen ${ }^{\mathrm{a}}$,

${ }^{a}$ Department of Energy Conversion and Storage, Technical University of Denmark, DK-4000 Roskilde, Denmark

${ }^{b}$ Department of Engineering "Enzo Ferrari", University of Modena and Reggio Emilia, Via Vignolese 905, I-41125

Modena, Italy

\section{Highlights}

1. - Loss of transformation toughening and R-curve effect for high porosities (>50 \%)

2. - First measurement of R-curve in porous 3YSZ

3. - Increase of flaw tolerance for higher porosities

Keywords:

Yttria stabilized zirconia

Porosity

Mechanical properties

Anode supported solid oxide fuel cell

\begin{abstract}
3YSZ specimens with variable open porosity ( 1 to $57 \%$ ) were fabricated, and the stiffness, strength and fracture properties (fracture toughness and R-curve) were measured to investigate their potential use as support structures for solid oxide fuel or electrolysis cells. The ball-on-ring test was used to characterize Young's modulus and Weibull strength. The variation of fracture toughness with porosity was investigated and modelled using the results from fracture mechanical testing. A distinct R-curve behaviour was observed in dense 3YSZ specimens, in samples with a porosity around $15 \%$ and in some of the highly porous samples (porosities $\sim 45 \%$ ) reflecting a transformation toughening in the material.
\end{abstract}


For the most porous samples, the "R-curve behaviour" disappeared and subcritical crack growth was observed. The studies indicate that even highly porous 3YSZ structures (porosities exceeding $40 \%$ ) are feasible supports for SOFC/SOECs from a mechanical point of view.

\section{Introduction}

Solid oxide cells (SOCS) are high temperature electrochemical devices that can be operated as solid oxide fuel cells (SOFC) to transform fuel to electricity or "in reverse" in electrolysis mode (SOEC) to convert electricity and $\mathrm{H}_{2} \mathrm{O}$ and/or $\mathrm{CO}_{2}$ to fuel (hydrogen and/or synthesis gas/CO). An important and much studied SOC design employs the Ni-YSZ (Yttria stabilized zirconia) fuel electrode as the mechanical support in the cell, typically with a thickness of 200-1000 $\mu \mathrm{m}$, on top of which a thin ( $10-20 \mu \mathrm{m})$ YSZ layer serves as the electrolyte. The Ni-YSZ support layer is made from a composite NiO/YSZ ceramic, which is reduced to a Ni-YSZ cermet during stack initiation. Ni-YSZ is the preferred material for both the support layer and the fuel electrode due to its good electronic conductivity, chemical and structural stability, catalytic properties and compatibility with the other materials in the SOFCs [1]. In most cases, the layers are fabricated starting from powders (NiO and YSZ) that are sintered at elevated temperatures $\left(>1200^{\circ} \mathrm{C}\right)$. A significant porosity is needed in the finished electrode to allow diffusion of gaseous species to the electrochemical active areas. Porosity is created by the $\sim 40 \%$ volume reduction associated with the reduction of $\mathrm{NiO}$ to $\mathrm{Ni} .8$ mol\% $\mathrm{Y}_{2} \mathrm{O}_{3}$-doped $\mathrm{ZrO}_{2}$ is one of the compositions showing the best ionic conductivity [2] and is therefore commonly used in the active fuel electrode layer (i.e. Ni8YSZ). 3 mol\% $\mathrm{Y}_{2} \mathrm{O}_{3}$-doped $\mathrm{ZrO}_{2}$ has been demonstrated to possess higher mechanical strength [3] than 8YSZ and is therefore advantageous to use in the support layer (i.e. Ni-3YSZ).

A novel SOC support design based on a sintered porous 3YSZ support (i.e. without NiO) was recently proposed in Ref. [4]. In this design, the support can be placed on either the fuel or oxygen side of the cell, and the electronic conduction is obtained by infiltrating the support of porous 3YSZ with conductive materials, e.g. Ni or $\mathrm{La}_{0.6} \mathrm{Sr}_{0.4} \mathrm{CoO}_{3}$. A high porosity is required in the ceramic support in order to obtain electronic percolation in the infiltrated phase. Thus, as reported in [5], porosities as high as $~ 50 \%$ may be required for infiltration based electrodes. The initial results [Ref. 4] indicated that the novel support design possessed adequate mechanical and electrical properties (see reference [4] for more details), however a full mechanical characterization of the porous 3YSZ layers, e.g. measurement of fracture toughness was not carried out. 
Materials designed for supports in SOCs environments require adequate mechanical properties at room temperature to tolerate handling during stack manufacturing. They must also withstand the mechanical stresses arising from both mechanical loading and thermal gradients during operation. The mechanical properties of the NiO-YSZ and Ni-YSZ cermets after reduction have been extensively studied in literature [6-12]. Radovic et al. [6] used the ring-on-ring method and fitted the Weibull strength-porosity data using a power law (such as eq. 12 in this work) for NiO-8YSZ anode supports. They obtained $\sigma_{0 d}=158$ $\mathrm{MPa}$ and $\mathrm{b}_{\sigma}=2.58\left(\mathrm{R}^{2}=0.962\right)$ for unreduced and $\sigma_{0 d}=473 \mathrm{MPa}$ and $b_{\sigma}=5.12\left(\mathrm{R}^{2}=0.965\right)$ for reduced anode material $\left(\sigma_{0 d}\right.$ is the strength of the non-porous structure, while $b_{\sigma}$ is an empirical parameter, see below the Strength-porosity correlation chapter). The effective volumes of the data presented by Radovic et al. are reported in the paper of Nakajo et al. [13]. Frandsen et al. [8] obtained $\sigma_{0 d}=776 \mathrm{MPa}$ $\left(V_{\text {eff }}=1 \mathrm{~mm}^{3}\right)$ and $b_{\sigma}=8\left(\mathrm{R}^{2}=0.8\right)$ for NiO-3YSZ also using eq. 12 to anlyse the data. In Frandsen it was proposed that the relatively stronger decrease of strength with increasing porosity was due to a loss of the phase transformation effect at higher porosities. This was however not investigated further.

The diminution of strength and Young's modulus as function porosity of NiO-YSZ and Ni-YSZ has also been investigated in other studies [6-8] and fracture toughness and subcritical crack growth in solid oxide cell anodes made of NiO-3YSZ or 8YSZ has been discussed in References 10-12. However, less data exist on the mechanical properties of pure and highly porous 3YSZ, which is the matter of this paper [14].

Pabst et al.[15] has reviewed the literature on relationships between elastic modulus and porosity in ceramics. Many semi-empirical equations have been developed to model this relationship with primary success for isotropic materials having porosities between 10 and $40 \%$ by volume [16]. These relationships do not adequately predict experimental data for materials with higher porosity $(>0.45$ volume fraction) $[15,16]$, where better predictive tools are still in need.

The ability of a ceramic material to withstand thermal stresses is directly proportional to its strain at failure [17]. Furthermore, strains, bending, and creep arising from thermal gradients, can occur at high temperature during SOC operation and cause failure in the materials and at interfaces between dissimilar materials. Therefore, strain at failure is also an important parameter to consider in design of SOFC anodes.

Rising fracture resistance with crack extension ( $R$-curve behaviour) is a well-known behaviour for dense partially stabilized zirconia (PSZ), [12,18-23]. R-curve behaviour has been attributed to crack shielding 
produced mainly by three different toughening mechanisms: transformation toughening, transformation induced microcrack toughening, and crack deflection toughening [24]. The transformation toughening effect is due to the fact that, at sufficiently high stress, metastable particles undergo a transformation from tetragonal to monoclinic, which is accompanied by a volume increase of $4 \%$ [24]. Since the transformation is stress induced, a zone of material containing transformed particles surrounds the crack tip after the critical transformation stress has been exceeded [25]. The non-linear stress-strain behaviour associated with the phase transformation and the different unloading stressstrain behaviour results in toughening as material points in the wake of the crack unload as the crack tip advances [25].

Subcritical crack growth (SCCG) is another important phenomenon observed in YSZ well documented in literature $[3,6,10-12,26]$. Generally, in truly brittle ceramic materials, crack growth occurs at a velocity that is on the order of magnitude of the speed of sound (fast fracture) after the applied energy release rate reaches a critical value $\left(G_{I C}\right)$. However, in some materials, including ceramics, crack growth can occur at lower velocities and this phenomenon is called subcritical crack growth (SCCG) [27-29]. SCCG can occur in reactive specimens due to weakening of inter-atomic bonding at the crack tip by chemical interaction with the environment or by transport of molecules to the crack front [26]. A higher water vapour pressure in the environment increases the crack growth rate by favouring the cleavage of $\mathrm{Zr}-\mathrm{O}-\mathrm{Zr}$ bonds at the crack tip [3]. SCCG has been observed and reported in different YSZ composites relevant for SOFC [10-12]. Atkinson et al. [10] observed SCCG in tape-cast 8YSZ; while Goutianos et al. [12] reported the results of SCCG for NiO-3YSZ anode supports. Radovic et al. [6] studied the variation of the fracture toughness of NiO-8YSZ and Ni-3YSZ vs. porosity, but no indication of SCCG was reported, despite that the technique employed (double torsion method) enables detection of slow crack growth [30].

In this work, we prepared structures with spherical pores formed by adding different amounts of PMMA (cf. the experimental section) to the slurries prior to tape casting. The obtained samples have porosities in the range from 1 to $57 \%$. The strength and elastic modulus was measured and modelled as a function of porosity. A fracture mechanical investigation was also carried out involving examining for R-curve behaviour as well as SCCG.

\section{Theory}

\section{Calculation of strengths}


In the ball-on-ring method, which was applied here, the highest tensile stress appears in the bottom of the ceramic supports below the centre of the ball. This equi-biaxial stress is determined by the elastic small displacement solution for a homogeneous specimen as follows [31]:

$\sigma_{\max }=\frac{6 M}{h^{2}}$

where $M$ is the maximum bending moment and $h$ the specimen thickness. The maximum bending moment $(M)$ is given by [31][32]:

$M=\frac{(1+v) F}{8 \pi}\left[1+2 \ln \left(\frac{a}{b}\right)+\frac{1-v}{1+v}\left(1-\frac{b^{2}}{2 a^{2}}\right) \frac{a^{2}}{R^{2}}\right]$

where $F$ is the load, $v$ the Poisson ratio, $a$ is the radius of the ring, $b$ the radius of the ball and $R$ the radius of the disk.

Weibull analysis and statistics were applied on the obtained strength data to evaluate the Weibull strength $\left(\sigma_{0}\right)$ and the Weibull modulus $(m)$ characteristic of the distribution of strengths over the ca. 30 samples investigated. The failure in a ceramic component occurs due to a significant flaw in the tensile stress region near the highest occurring tensile stress. The distribution of flaws results in a distribution of strengths for the different disks. The probability of failure $P_{f}$ in the Weibull distribution at a given stress $\sigma$ is calculated by [33]:

$P_{f}=1-\exp \left\{-\int_{\mathrm{V}}\left(\frac{\sigma}{\sigma_{0}}\right)^{\mathrm{m}} \frac{\mathrm{dV}}{\mathrm{V}_{0}}\right\}$

$\sigma_{0}$ is the Weibull strength in a reference volume $V_{0}$ and $m$ is the Weibull modulus. Eq. 3 can be rewritten as

$P_{f}=1-\exp \left\{-\left(\frac{\sigma_{\max }}{\sigma_{0}}\right)^{\mathrm{m}}\right\}$

where $\sigma_{\max }$ is the failure stress in a sample with an effective volume of $\mathrm{V}_{\text {eff }}$ given by

$V_{e f f} \equiv V_{0}=\int_{\mathrm{V}}\left(\frac{\sigma}{\sigma_{\max }}\right)^{\mathrm{m}} \mathrm{dV}$

Merging Eq. 4 and Eq. 5 provides Eq. 3. The effective volume $V_{\text {eff }}$ corresponds to the volume of a uniaxially tensed specimen with equal probability of failure as the ball-on-ring specimen at the same 
maximum stress. Inserting the stress distribution for the ball-on-ring specimen obtained in [31] into Eq. 5, the effective volume can be calculated. This was done analytically in ref. [34] and the equations there derived are used in this work.

Then the Weibull strength $\left(\sigma_{0}\right)$ and the Weibull modulus $(m)$ is obtained by linear regression of the data to a linearized form of Eq. 4, see e.g. [8].

\section{Determination of Young's Modulus}

The elastic modulus was also determined from the analysis of the ball-on-ring load-deflection curves. The displacement field solution for the ball-on-ring problem is reported in Eq. 31 of ref. [31]. In particular, for $0 \leq r<b$, the solution is:

$w(r)=\frac{q b^{4}}{16 D}\left\{-\frac{r^{4}}{4 b^{4}}+\left[1+2 \ln \left(\frac{a}{b}\right)+\frac{1-v}{1+v}\left(1-\frac{b^{2}}{2 a^{2}}\right) \frac{a^{2}}{R^{2}}\right] \frac{r^{2}-a^{2}}{b^{2}}+\left[\ln \left(\frac{a}{b}\right)-\frac{1}{2}\right] \frac{2 a^{2}+b^{2}}{b^{2}}+\frac{7}{4}\right\}$

Where $w$ is the vertical displacement, $r$ is the radial coordinate, $b$ : radius of the ball, $a$ is the radius of the ring, $R$ is the radius of the sample, $v$ is Poisson's ratio of the ceramic specimen, $h$ is the thickness of the specimen, $D$ is the bending stiffness of the sample and $q$ is the applied surface load from the contacting ball. A Poisson's ratio value of $v=0.3$ was used in Eq. 6 based on the values reported in ref. [35] for stabilized $\mathrm{ZrO}_{2}-\mathrm{Y}_{2} \mathrm{O}_{3}$ ceramics. In fact, in this paper, Poisson's ratios $(v)$ of 0.30 to 0.31 were found for stabilized $\mathrm{ZrO}_{2}-\mathrm{Y}_{2} \mathrm{O}_{3}$ ceramics increasing slightly with decreasing porosity. Thus we have assumed a constant value of $v=0.3$ for all the samples here investigated. However, it should be noted, extrapolating from well-known porosity-Poisson's ratio correlations, e.g. see below Eq. 7 taken from ref.[8][36] , that a decrease of the Poisson's coefficient to 0.24 could be expected for high porosities in the range of $57 \%$.

$v=\frac{1}{4} \frac{4 v_{0}+3 P-7 v_{0} P}{1+2 P-3 v_{0} P}$

The bending stiffness is defined as

$D=\frac{I E}{1-v^{2}} \quad$ where $\quad I=\frac{1}{12} h^{3}$

The piston displacement, which corresponds to the displacement at the centre of the disc $(r=0)$ is recorded in the experiments. The force applied , $F$, equals $q \pi b^{2}$ ( $q$ is assumed to be evenly distributed 
surface load over the ball contact area [30]) and Young's modulus, E, can thus be determined from Eq. 6 and 7 to be:

$$
E=\frac{F}{w} \frac{b^{2}\left(1-v^{2}\right)}{16 \pi I}\left\{-\left[1+2 \ln \left(\frac{a}{b}\right)+\frac{1-v}{1+v}\left(1-\frac{b^{2}}{2 a^{2}}\right) \frac{a^{2}}{R^{2}}\right] \frac{a^{2}}{b^{2}}+\left[\ln \left(\frac{a}{b}\right)-\frac{1}{2}\right] \frac{2 a^{2}+b^{2}}{b^{2}}+\frac{7}{4}\right\}
$$

where $F / w$ is the slope of the load displacement curve (for each of the samples).

An initial deviation from linearity in the load deflection curve, which is due to gradual establishment of full contact is disregarded when deriving E from Eq. 8.

\section{Calculation of failure strain}

The failure strain was calculated from the ratio between the Weibull strength $\left(\sigma_{0}\right)$ and Young's modulus $(E)$ of the specimens determined by ball-on-ring method:

$\varepsilon_{y y}=-v \frac{\sigma_{x x}}{E}+\frac{\sigma_{y y}}{E}=>\varepsilon_{f}=(1-v) \frac{\sigma_{0}}{E}$

Where $\sigma_{0}=\sigma_{x x}=\sigma_{y y}[31]$.

\section{Elastic modulus-porosity correlation}

In the present work, the following two equations describing elastic moduli as a function of porosity were used to fit the experimental Young's modulus-porosity data.

$E=E_{0} e^{-b_{E} P}$

$E=E_{0} \frac{(1-P)^{2}}{1+b_{E} P}$

where $E_{0}$ is the elastic modulus of the fully dense material, $b_{E}$ is a fitting constant and $P$ is the porosity. The exponential equation (Eq. 10) was proposed by Spriggs [37] and Rice [38] showed that the $b_{E}$ is related to particle stacking and pore shape in the "minimum solid area" model. The second model, represented by Eq. 11, was developed by Ramakrishnan and Arunachalam [39] for randomly distributed pores on the basis of the "composite spheres model" (CSM) [40].

\section{Strength-porosity correlation}


Accurate prediction of the fracture strength of porous ceramics in general requires that adequate information on pore shape and orientation are included, in addition to pore volume (fraction), as parameters as these influence the fracture strength-porosity relationships. The theoretical and experimental studies in literature can be divided in two main groups: a) those that consider only a pore volume fraction effect on strength [38], and b) those involving also a pore structure (size and orientation) effect on the mechanical strength $[41,42]$. Two different general approaches have thus been developed to explain or predict the fracture strength-porosity correlation in ceramic materials. One approach [38] generally called the minimum contact area model (MCA), suggests that the strength of ceramics is dependent on the minimum contact area through the solid. According to this model, the mechanical strength decreases exponentially with increases in volume fraction porosity $(P)$ according to Sprigg's [37]:

$\sigma=\sigma_{0 d} e^{-b_{\sigma} P}$

where $\sigma_{0 d}$ is the strength of a fully dense material, while $b_{\sigma}$ is an empirical parameter related to the minimum solid area and dependent on the pore structure [38]. In ref. [38] Rice showed that Eq. 12 can be applied for describing strength-porosity correlation for a wide range of different materials for which the decrease of strength with porosity is proportional to the decrease of elastic modulus with porosity according to the minimum solid area model. Eq. 12 does not consider pore interactions that occur at high porosity and it is therefore limited to a porosity range up to approximately $40 \%$ [43].

In the second approach, referred to as the stress concentration effect model (SCE) $[41,42]$, it is suggested that strength is dependent on pore shape and resulting stress concentrations. According to this model, the strength-porosity relationship for porous samples is given by a power-law type expression:

$\sigma=\sigma_{0 \mathrm{~d}}(1-\mathrm{P})^{b_{\sigma}}$

where the exponent $b_{\sigma}$ is related to the pore structure (shape and orientation of spheroidal pores with respect to the stress axis) and on the Poisson's ratio of the material $[41,42]$ as given by:

$b_{\sigma}=1.21\left(\frac{\mathrm{z}}{\mathrm{x}}\right)^{\frac{1}{3}} \sqrt{1+\left[\left(\left(\frac{\mathrm{z}}{\mathrm{x}}\right)^{-2}-1\right]\right.} \cos ^{2} \emptyset$ 
where $(z / x)$ is a shape factor, defined by the axial ratio of the substitutional spheroids; and $\cos ^{2} \emptyset$ is the orientation factor, where $\emptyset$ is the angle between the stress direction and the rotational axis of the substitutional spheroid.

\section{Calculation of fracture toughness}

\section{Calculation of fracture toughness from double cantilever beam (DCB) experiments}

The chosen method for the fracture mechanical characterization is the double cantilever beam (DCB) method, where specimens are loaded with pure bending moments. In order to facilitate testing of the thin ceramic samples at hand, we use a test specimen configuration where a steel beam is bonded onto the ceramic as proposed in Ref. [12].

In a DCB set-up subjected to pure bending moments, the strain varies linearly across the height (if the beams are a few times longer than their height). Under these conditions, the $J$ integral, for plane stress, is given by Goutianos et al. [12]:

$J=\frac{1}{E_{2}} \frac{M^{2}}{B^{2} h^{3} I_{0}}$

where $E_{2}$ is the Young's modulus of the steel beams, $B$ is the width of the steel beams, $M$ is the applied moment and $h$ is the height of the purely ceramic part of the sample as defined in ref. [12]. Equation 15 is similar to the energy release rate formula for sandwich specimens of Bao et al.[44]. The nondimensional constant $I_{0}$, which differs from that of Bao et al. [44] due to the different widths of the two materials, depends on geometry and elastic constants [44]:

$I_{0}=\frac{1}{3}\left[\frac{1}{n^{3}}+\frac{3 \Delta}{n}\left(\Delta-\frac{1}{n}\right)+\xi \bar{\Sigma}\left(1+3\left(\Delta+\frac{1}{n}\right)^{2}-3\left(\Delta-\frac{1}{n}\right)\right)\right]$

where $\Delta$ is equal to:

$\Delta=\frac{1+2 \xi n \bar{\Sigma}+\xi n^{2} \bar{\Sigma}}{2 n(\xi n \bar{\Sigma}+1)}$

with $n=\frac{h}{H}$ and $\bar{\Sigma}=E_{1} / E_{2}$, and where $H$ is the height of the steel beams, $E_{1}$ is the Young's modulus of the sample and $\xi=b / B$, where $b$ is the width of the ceramic layer. Finally, from the value of the $J$ integral at crack propagation the critical energy release rate, $G_{I c}$, can be calculated, taking into account 
that the energy is released from the beams of width $B$, but energy is consumed by the fracture process over the width of the ceramic sample $b$ only:

$J_{I C} B=G_{I c} b=>G_{I C}=J_{I c} / \xi$

From $G_{I c}$ under elastic conditions, the critical plane stress Mode I stress intensity factor can be evaluated by [45]:

$K_{I c}=\sqrt{G_{I C} E_{1}}$

Increase in fracture toughness from transformation toughening

The rising fracture toughness $\left(K_{R}\right)$ of zirconia ceramics is the result of a stress induced local martensitic transformation from tetragonal to monoclinic structure at the crack tip region. The tetragonal to monoclinic (t-m) transformation is accompanied by a volume expansion, which can be modelled as a non-reversible (history dependent), non-linear stress-strain law. The stress-induced transformation occurring at the crack tip produces a transformation zone of height $2 \mathrm{~d}$. In most of the mechanistic models of transformation toughening, the formation of the initial transformation zone at the tip of a stationary crack has no net effect on the toughness of the material [46]. However, as the crack grows, material unloading occurs in the transformed material behind the crack tip. It is the non-reversible stress-strain behaviour (the stress-strain relation during unloading differs from the stress-strain relation during loading) that a material point undergoes as it "passes by" the crack tip to the wake that lead to an increase in fracture toughness. The phenomenon of rising fracture toughness with increasing crack length is called R-curve behaviour [12,18-22].

The extent of the transformation at the crack flanks is important parameter, which depends on temperature, the amount and type of stabilizer used, and the size of tetragonal zirconia particles. The maximum capability of a material to exhibit transformation toughening can be expressed as a shielding stress intensity factor, $\Delta K_{R_{S S}}$, which is a function of the transformation zone shape, as evaluated by the parameter $\eta$, and the zone size $(d)$. Thus, the increase in toughness from initiation $K_{R_{0}}$ to steady-state, $K_{R_{S S}}$, resulting from stress-activated transformation, $\Delta K_{R_{S S}}$, is commonly given by an expression of the form [18]:

$\Delta K_{R_{S S}}=\frac{\eta E e_{T} V_{f} d^{1 / 2}}{1-v}$ 
where $\eta$ is a factor depending on the zone shape at the crack tip and the nature of the stress field in that zone. $E$ is the effective modulus of the material, $e_{T}$ is the dilatational strain, $V_{f}$ is the transformed volume fraction of particles, $d$ is the width of the transformation zone from the crack surface (i.e., the half-height of the zone), and $v$ is the Poisson ratio. Different values for $\eta$ have been proposed depending on the elongation of the zone ahead of the crack tip [18].

\section{Phenomenological models of R-curve behaviour}

When R-curve behaviour occurs, the stress intensity factor required for crack propagation, $K_{R}$, can be written:

$K_{R}=K_{R_{0}}+\Delta K_{(\Delta a)}$

where $K_{R_{0}}$ is the stress intensity factor at the crack tip of the existing flaw (crack tip fracture toughness) and $\Delta K_{(\Delta a)}$ is the fracture toughness increase that depends on the crack extension, $\Delta a$. Evans [47] has suggested an empirical function to fit the R-curve:

$\Delta K_{(\Delta a)}=K_{0} \arctan \left(\frac{\Delta a}{d}\right)$

where $K_{0}=\left[\frac{\beta}{1-v}\right] E e_{T} V_{f} d^{1 / 2} ; \beta$ is another constant and the normalizing parameter $d$ is the zone width. Here, we will treat Eq. 22 simply as an empirical function chosen to fit the R-curve.

Another empirical fit to R-curves was introduced by Shetty et al. [48]:

$\left.K_{R}=K_{R_{S S}}-\left(K_{R_{S S}}-K_{R_{0}}\right) e^{\left(-\frac{\Delta a}{\lambda}\right)}\right]$

The parameter $\lambda$ reflects the range of crack extension over which toughening effects should develop and saturate [48]. In other words, $\lambda$ may be used as a rough measure for the size of the steady-state process zone formed behind the crack-tip during crack extension [49].

Cook and Clarke used a simple power law [50] to describe the crack length dependence of fracture toughness while Munz and Fett in ref. [51] and Ramachandran and Shetty in ref. [48] employed exponential R-curve equations. 
In this paper, in addition to the arctan model given by Evans [47] (Eq.22), we have used the model given by Shetty (eq. 23) [48] to fit the R-curve data.

\section{Fracture strength-R-curve correlation}

R-curve behaviour can cause crack growth to be initially stable followed by unstable crack propagation. Unstable fracture occurs when the following two conditions are met [52]:

$K=K_{R}$

$\frac{d K_{I}}{d a}>\frac{d K_{R}}{d a}$

Thus, in case a material's R-curve behaviour is known (described in a mathematical form), it is possible to assess the critical stress $\left(\sigma_{f p}\right)$ and the critical crack length for instability $\left(a_{0}\right)$ by simultaneously solving the equilibrium fracture (eq. 24) and the instability (eq. 25) equations. One example is given by Heuer [52]. Heuer et al. resolved this system of equations in ref. [52], by using the R-curve model given by Evans (arctan cruve of eq.22) in ref.[47], and from the usual criterion for brittle fracture. The critical crack extension at failure is deduced to be:

$\Delta a_{f}=\left[\frac{2}{(\pi)^{\frac{1}{2}}}\right]\left(a_{0} d\right)^{\frac{1}{2}}$

where $\mathrm{a}_{0}$ is the critical crack length for instability. The fracture strength $\left(\sigma_{f p}\right)$ is given by:

$\sigma_{f p}=\left[K_{G}+\Delta K_{\left(\Delta a_{f}\right)}\right] /\left(Y\left(a_{0}+\Delta a_{f}\right)^{\frac{1}{2}}\right)$

where $Y$ can be assumed to be 1.2 for an elliptical crack. The exact form of the R-curve, $\Delta K_{(\Delta a)}$, i.e., how rapidly the crack resistance increases with increasing crack length, determines the fracture strength [52].

In this paper, we have used Eq. 22 and 23 to fit R-curve data and Eq. 26 and 27 to relate fracture toughness data from DCB with the fracture strength determined by ball-on-ring measurements allowing an estimate of the critical crack length and instability crack extension.

Conditions for stable crack growth in $D C B$ 
For the fracture mechanical testing method, the double cantilever beam (DCB) specimen loaded with pure bending moments, $K_{I}$ is independent of the crack length, $\Delta a$, according to Eq. 15-19. It follows that $\frac{\partial K_{I}}{\partial a}=0$ (constant moment). This testing method will thus provide stable crack growth even in materials with constant fracture toughness. Crack growth will then take place in small increments. This will enable the measurement of the fracture toughness as a function of crack extension and thus facilitate the measurement of the entire R-curve from onset of cracking to steady-state cracking. This is the prime advantage of the DCB loaded with pure moments [53].

\section{Conditions for SCCG behaviour}

SCCG occurs when the applied stress intensity factor necessary to cause crack initiation from a stationary sharp crack $K_{I c}^{i}$ is exceeded. It can be different from $K_{I c}^{a}$, expressing the level below which to unload to arrest a propagating crack [11]. The applied stress intensity factor causing fast fracture (the crack grows at a velocity about a third of the speed of sound) is denoted by $K_{I c}^{f}$. Assuming a small scale transformation zone, the critical plane stress Mode I stress intensity factor can be determined under elastic conditions from $K_{I c}^{f}[11]$ from Eq. 19. The stress intensity factor for fast fracture $K_{I c}^{f}$ is, of course, higher than the critical stress intensity factor for crack initiation $K_{I c}^{i}$ and crack arrest $K_{I c}^{a}$. The procedure to characterize the SCCG is given below.

SCCG is determined by applying increased bending moments to the DCB sample resulting in stress intensity factors larger than $K_{I c}^{i}$ and observing the rate at which the crack propagates. After this the bending moments are decreased below $K_{I c}^{a}$. The stress intensity factor is then increased sequentially until $K_{I C}^{f}$ and instantaneous failure is observed.

\section{Experimental methods}

\section{Materials and processing}

Porous 3 mol\% yttria stabilized zirconia (3YSZ) supports (hereafter also called backbones) with different levels of open porosity $\left(P_{0}\right)(1-57 \%)$ and closed porosity $\left(P_{c}\right)$ were prepared by tape casting. An overview of the prepared samples and sample nomenclature is given in Table 1. The tape casting slurries were made using ethanol as solvent and contained poly-methyl methacrylate as pore former (PMMA 7-10 $\mu \mathrm{m}$ from Esprix) and an in-house binder-dispersant system added to the 3YSZ powder (Tosoh Co.), as described in [4]. All the powders were used as-delivered, except for the BB010 formulation, where 50 
wt $\%$ of the $3 Y S Z$ powder was pre-calcined at $1100^{\circ} \mathrm{C}$ for $2 \mathrm{hs}$. In tape BB09, $10 \mathrm{wt} \%$ of the $3 \mathrm{YSZ}$ was substituted with randomly distributed 10YSZ fibers from Zircar Zirconia Type ZYBF, Inc. (Florida, NY, USA). The specific surface area of the fibers is $4 \mathrm{~m}^{2} / \mathrm{g}$, the diameter from 6 to 10 microns and the length about few hundred microns. The dried tape cast layers were laminated to obtain thicker samples yielding better handling strength. Circular samples were punched out of the laminates to a diameter of ca. $25 \mathrm{~mm}$ and a thickness of ca. $300 \mu \mathrm{m}$ and sintered at a temperature of $1315^{\circ} \mathrm{C}\left(15^{\circ} \mathrm{C} / \mathrm{h}\right.$ to $600 \mathrm{C}^{\circ}$ for 4 $\mathrm{h} ; 60^{\circ} \mathrm{C} / \mathrm{h}$ to $1315^{\circ} \mathrm{C}$ for $12 \mathrm{~h} ; 100^{\circ} \mathrm{C} / \mathrm{h}$ to $25^{\circ} \mathrm{C}$ end). For each type of backbone, between $29-40$ samples were fabricated for ball-on-ring testing. Samples for other mechanical tests were made by laser cutting of the sintered samples into the appropriate size (sample sizes are reported below).

Similarly, circular samples of tape cast NiO-3YSZ support layers were fabricated by punching and sintering to a diameter of ca. $25 \mathrm{~mm}$ and $300 \mu \mathrm{m}$ thickness. The samples were reduced to Ni-3YSZ by exposure to an atmosphere of $9 \% \mathrm{H}_{2}-\mathrm{Ar}$ at $1000^{\circ} \mathrm{C}$ over $6 \mathrm{~h}$. In order to eliminate $\mathrm{Ni}$ and produce $3 \mathrm{YSZ}$ backbones from reduced samples, some of these reduced samples were further exposed to concentrated nitric acid (70wt\% concentrated $\mathrm{HNO}_{3}$ from Sigma-Aldrich) at room temperature under well-stirred conditions. The acid treatment resulted in complete removal of the Ni phase (based on weight changes), and the samples consisted subsequently of highly porous 3YSZ backbone. Respectively, 29 and 30 samples of the reduced and acid treated samples were fabricated and mechanically tested.

\section{Microstructural characterization}

The porosity and pore size distribution of the porous samples were determined by mercury intrusion using an Autopore IV 9500V1.05 from Micromeritics Instrument Corporation, Norcross, GA. Due to the uncertainty of the mercury intrusion porosimeter for highly dense materials, the porosity of the dense sample was measured on an AccuPyc-1340 Helium Pycnometer. Scanning electron microscopy (Hitachi TM1000 tabletop SEM) was performed on the sintered samples to investigate their microstructure. Prior to SEM investigation, the samples were vacuum embedded in Epofix (Struers, Denmark), ground and polished to $1 \mu \mathrm{m}$, and coated with carbon to eliminate surface charging.

\section{Tensile strength by Ball-on-ring}

Tensile strength was determined by the ball-on-ring method by means of an Instron testing machine (Model 1362 graded to 88R1632). The displacement is measured using an LVDT (linear variable differential transducer, range $\pm 50 \mathrm{~mm}$, resolution $\pm 2.5 \mu \mathrm{m}$ ) located in the Instron drive unit. The 
diameter of the supporting ring was $16 \mathrm{~mm}$, while the diameter of the ball was $3.96 \mathrm{~mm}$. The loading speed was $0.2 \mathrm{~mm} / \mathrm{min}$.

\section{Determination of Young's Modulus}

The elastic properties of the specimens were determined by the impulse excitation technique [54] using equipment from IMCE NV, Genk, Belgium. Rectangular bars of $15 \mathrm{~mm} \times 60 \mathrm{~mm} \times 0.3 \mathrm{~mm}$ were laser cut from the sintered tapes. The tests were conducted in accordance with the procedure described in Ref.[55] and in ASTM E 1876-99 standard. The ball-on-ring tests and IET measurements were performed at room temperature.

\section{Fracture toughness by Double cantilever beam (DCB)}

Rectangular specimens of $10 \times 60 \times 0.3 \mathrm{~mm}^{3}$ with a central notch $(25 \mathrm{~mm}$ long and $0.1 \mathrm{~mm}$ tall) along the biggest dimension where laser cut from the tapes. An additional micro-notch, needed to ensure that initial cracking take place in the middle of the ceramic layer, was introduced at the laser cut notch root with a steel blade. The experimental procedure for sample preparation follows that reported in ref. [12].

The ceramic layer was placed inside the grooves of two steel beams and glued using ScotchWeldcTMDP460 from 3M as two-part epoxy adhesive to form the test specimen. The height, $\mathrm{H}$, of the steel beams was $5.95 \mathrm{~mm}$ and the width, B, $4.85 \mathrm{~mm}$.

The DCB specimens were loaded with pure bending moments, using a special fixture that consists of grips that lies on a base fixture $[11,12,56]$. The DCB specimen loaded with pure bending moments is a steady-state specimen, as under constant moments, the energy release rate $(G)$ is independent of the crack length $(\Delta a)$ as seen from eq. (15-19) [56]. Only the measurement of the applied moment is necessary to calculate $G$.

The fixture was mounted on the XYZ stage of an optical microscope (DeltaPix, camera Infinity X-32) and thus by translating the stage in the specimen (XY) the crack growth can be measured by means of the optical microscope (Deltapix, Infinity X-32). The magnification used in the optical microscope was between 100-200X. All the tests were conducted at room temperature and in air.

Test procedure for measurement of the R-curve behaviour 
The experiments were performed under displacement control (i.e. under a constant crosshead speed) to obtain stable crack growth. The crack length is recorded prior to loading. The load $(P)$ is increased until crack growth is detected, then the specimen is unloaded, and the new crack length is measured. Then the load can be increased again until further crack growth has taken place, etc. The load at the onset of crack growth can be converted into a moment $(M)$ and the critical energy release rate $\left(G_{I c}\right)$ and stress intensity factor $\left(K_{I C}\right)$ can be calculated following the equations (15-19) reported in the theory section. The crack extension $(\Delta a)$ was measured by optical microscopy.

\section{Test procedure for measurement of SCCG}

First the DCB specimen was gradually loaded until a crack "popped in" at the root of the laser cut micronotch. The stress intensity factor at this first crack growth, from the rounded notch, is designated $K_{I c}^{*}$. Once a crack initiated at the micro-notch, it grew continuously if $K$ was not reduced. This is because $K_{I C}^{*}>K_{I C}^{i}$, as mentioned in the introduction and explained in detail in ref [12]. Then, the specimen was partially unloaded (the applied $K$ decreased around 30\%) to arrest the crack after it had grown approximately 250-500 $\mu \mathrm{m}$ (5-10 times the initial notch radius depending on the sample porosity). Then $K$ was increased until the crack grew again, which corresponds to $K_{I c}^{i}$, followed by a partial unloading ( $K$ was decreased about $8-10 \%$ ). This procedure (the last two steps) was repeated eight times for each specimen. After the measurements of $K_{I C}^{i}$, the crack growth velocity as function of $K$ was measured on the same specimen. The loading procedure was as follows:

a) The applied $K$ was increased rapidly (at a rate of $G \approx 6 \mathrm{~J} / \mathrm{m}^{2} / \mathrm{s}$ ) to a value larger than $K_{I c}^{i}$, for the specific specimen.

b) $K$ was kept constant for a time period $\Delta t_{i}$ (typically $30 \mathrm{~s}$ ).

c) The specimens were unloaded until $K<K_{I c}^{a}$ and the crack arrested.

d) The applied $K$ was held constant for a time period of $\approx 20 \mathrm{~min}$.

During step b) the crack propagated (crack increment) a distance $\Delta a_{i}$. Then the average crack growth velocity can be approximated as $v_{i}=\frac{\Delta a_{i}}{\Delta t_{i}}$. No significant decrease in applied $K$ was observed during crack propagation and no crack growth took place at $K<K_{I c}^{a}$. The applied $K$ at step d) corresponds to an applied energy release rate smaller than the applied energy release rate required for crack arrest, $K_{I c}^{a}$. A 
relatively large time period was selected for this step in order to ensure that no SCCG takes place at the applied $K$ during this step. The estimated $K_{I c}^{a}$ value reported in Table II is based on this time interval. The procedure described above was repeated several times (usually at a $K$ larger than at the previous step) until the case where the applied $K$ caused fast fracture of the specimen. In this case the crack growth velocity was estimated by the remaining uncracked specimen length and time to failure.

\section{Results}

\subsection{Microstructure}

Fig. 1 shows SEM micrographs of the porous backbone structures, evidencing the open pore size distributions of the investigated structures. The pore characteristics (porosity and average pore size based on volume, as derived from the mercury intrusion test) are included in Table 1. The samples with prefix BB were manufactured using PMMA as a pore former and therefore contain spherical pores in variable amounts as illustrated in Fig. 1 with porosity shown in brackets. The porosity of the sample 2G3YSZ (etch) was made by removing Ni from a cermet structure, and contains finer and more irregular pores as illustrated in Fig. 1g. The minor variations in pore size distribution observed between the samples with similar total open porosity (BB07, BB09, BB10, BB08 with respectively 46, 47, 49 and 54\% porosity, Table 1) are due to the addition of small amount of precalcined 3YSZ powder (BB10), or minor amounts of 10 YSZ fibers (BB09) as described in the experimental section. In particular, BB09 shows a less homogeneous microstructure, possibly due to the effect of a scarce fibre distribution during processing, given rise also to local agglomeration of pores. This later increases the length of the defects and possible initial flaws during fracture tests. 


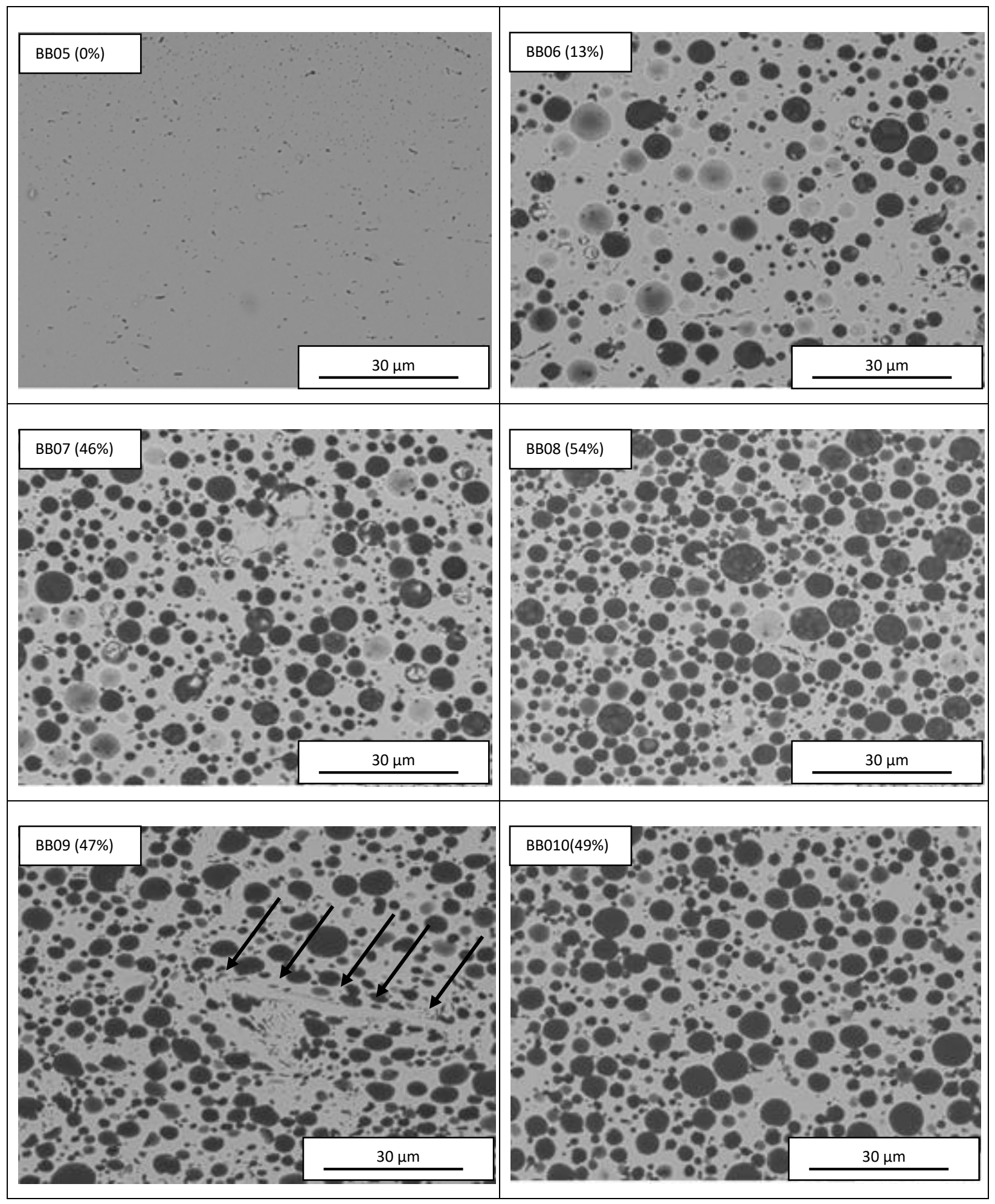




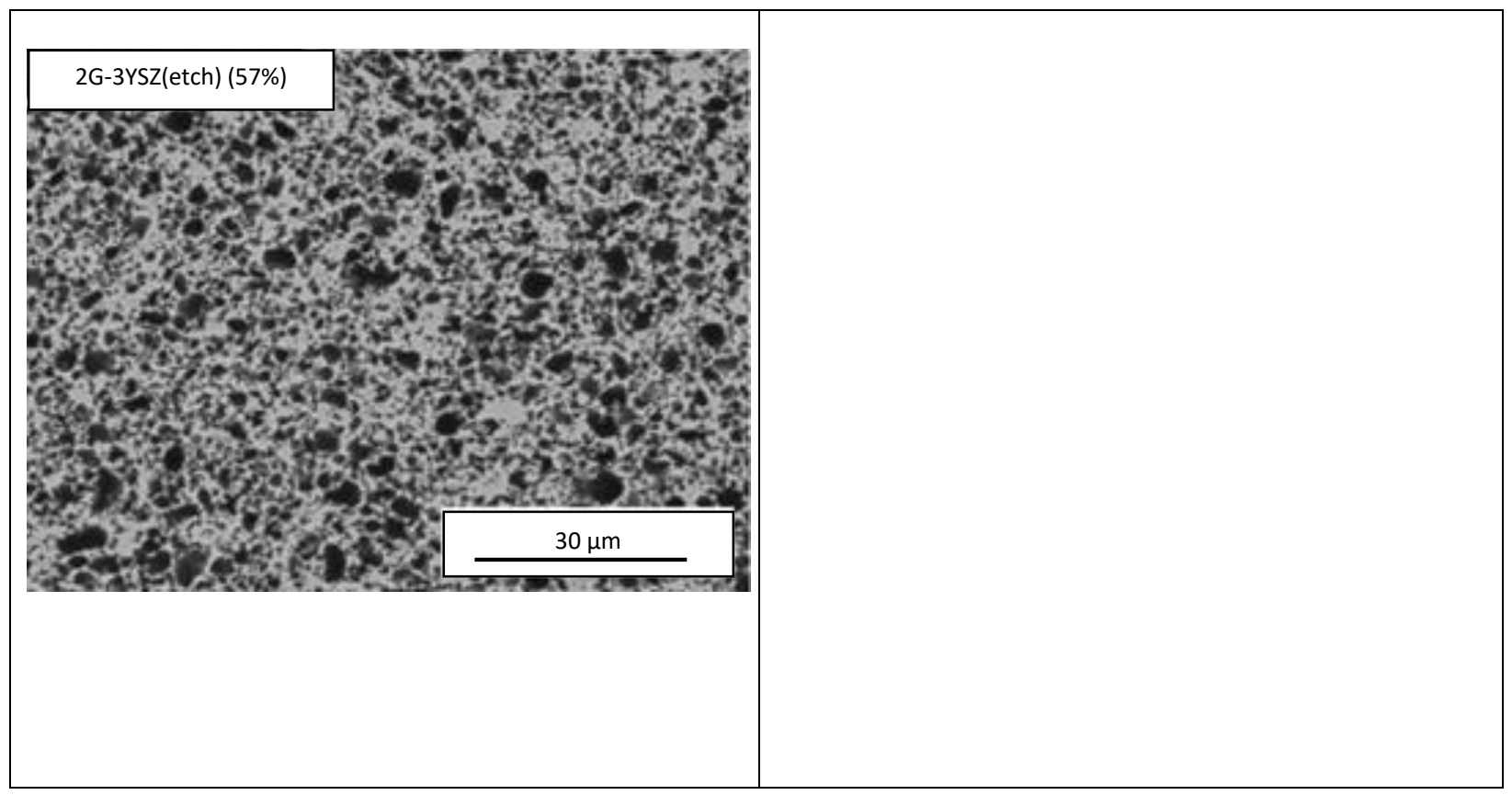

Fig. 1: SEM micrographs of the porous backbone structures. In BB09 the black arrows show a micro structural imperfection due to presence of a fibre

Table I: Overview of prepared and mechanically characterized samples. The porosity and average pore diameter is measured by mercury intrusion porosimeter. The relative standard deviation (RSD) of porosity is $5 \%$.

\begin{tabular}{ccccc}
\hline $\begin{array}{c}\text { Sample } \\
\text { name }\end{array}$ & Material & $\begin{array}{c}\text { Open } \\
\text { porosity }\end{array}$ & $\begin{array}{c}\text { Closed } \\
\text { porosity }\end{array}$ & $\begin{array}{c}\text { Average pore diameter } \\
(\%)\end{array}$ \\
$\begin{array}{cccc}(\%) \\
\text { BB05 }\end{array}$ & 3YSZ & 2.8 & - & - \\
BB06 & 3YSZ & 13 & 11 & 0.32 \\
BB07 & 3YSZ & 46 & 3 & 0.73 \\
BB08 & 3YSZ & 54 & 4 & 0.82
\end{tabular}


BB09

3YSZ and 10\% 10YSZ fibers

47

5

0.85

BB10 3YSZ and 50\% precalcined

49

0.79

2G-3YSZ 3YSZ cermet where $\mathrm{Ni}$ is

57

0.30

(etch)

removed

2G-DTU 3YSZ:Ni cermet (50:50)

30

0.36

\subsection{Mechanical properties}

Elastic properties and porosity correlation

In Fig. 2 the elastic moduli of the new 3YSZ anode supports (BB) are compared with data [8] on the conventional NiO-3YSZ half-cells $(\Delta)$ (i.e. a multilayer of NiO-3YSZ support, a NiO-8YSZ electrode, and an 8YSZ electrolyte) together with values for a reduced half-cell Ni-3YSZ (i.e. a multilayer of a Ni-3YSZ support, a Ni-8YSZ electrode and an 8YSZ electrolyte) [9,13] (Reduced at $600^{\circ} \mathrm{C}$ ). Fig. 2 also shows a new experimental value obtained in this investigation (labelled; 2G -DTU) corresponding to a pure Ni-3YSZ anode support and a data point obtained for this type of structure after etching away all Ni (2G-3YSZ)

The determination of the elastic modulus of the samples was performed by analysing the loaddeflection curves obtained from the ball-on-ring tests, Eq. (8). The deflection range used for elastic modulus determination was $0.005-0.1 \mathrm{~mm}$. Table II reports the values of the elastic moduli of the samples investigated in this paper, while Table III reports data from on NiO-3YSZ [8] and Ni-3YSZ [9] supported half-cells for comparison. 


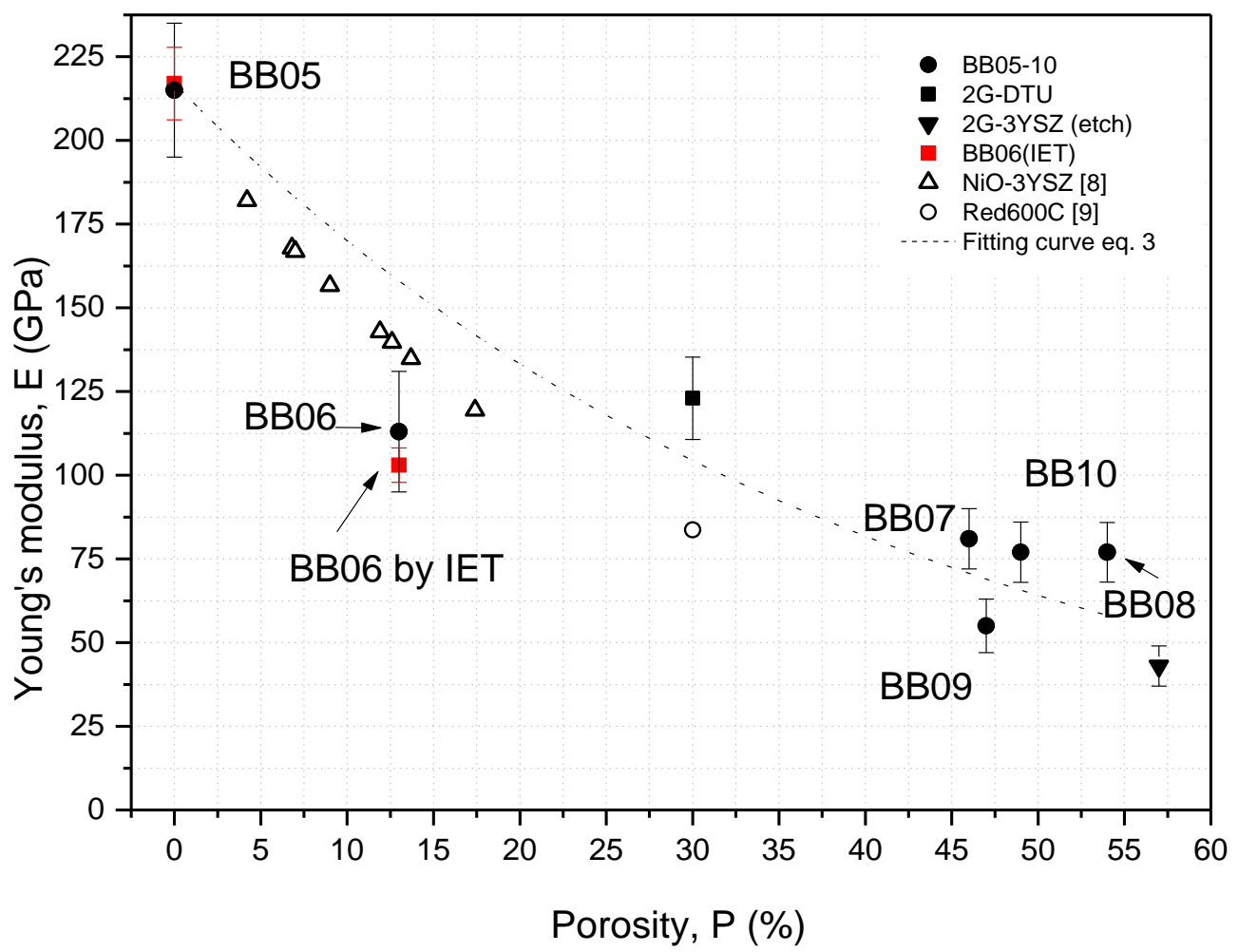

Fig. 2: $E$ modulus vs. porosity for the different materials investigated (SD of porosity: $5 \%$ ). A best fit curve of the BB05/6/7/8 data by the exponential model (eq. 10) is also plotted. Data from literature for NiO-3YSZ [8] and Ni-3YSZ (Reduced at $600^{\circ} \mathrm{C}$ ) [9] are also included (filled symbols were used to represent data from the present work)

Impulse excitation technique (IET) was also employed for the samples BB05 and BB06, and resulted in similar values to those obtained from the ball-on-ring load-deflection curves. It should be noted that half-cells are trilayer composites and the 3YSZ (BB) samples investigated here are basically monolithic material and the moduli are thus not directly comparable.

Table II: Sample microstructural characteristics and calculated mechanical parameters from ball-onring tests of 3YSZ (BB) and Ni-3YSZ (2G-DTU) samples

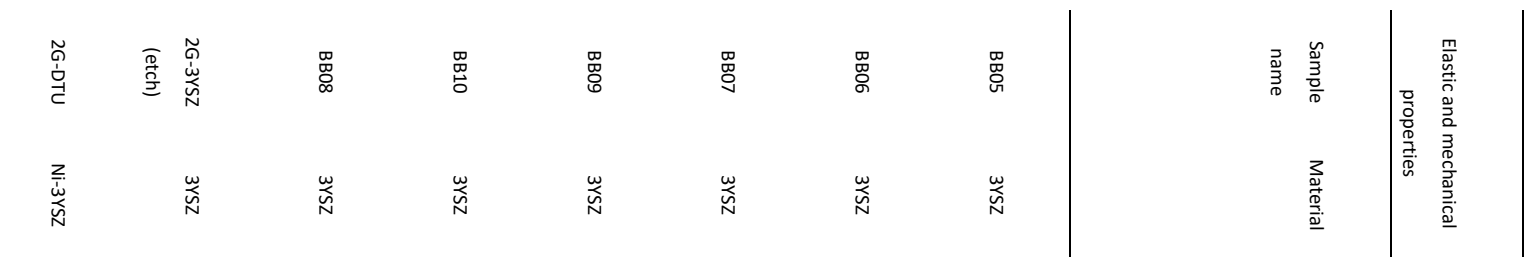




\begin{tabular}{|c|c|c|c|c|c|c|c|c|c|c|}
\hline D & w & D & D & D & D & in & D & 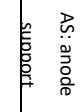 & 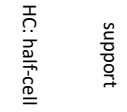 & 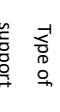 \\
\hline $\begin{array}{l}\dot{0} \\
\stackrel{\sim}{\sim} \\
\dot{0} \\
\dot{0}\end{array}$ & 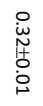 & 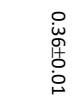 & $\begin{array}{l}\stackrel{0}{ } \\
\dot{w} \\
\text { ồ } \\
\dot{0}\end{array}$ & 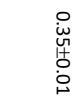 & 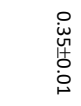 & $\begin{array}{l}\dot{0} \\
\dot{w} \\
+ \\
\dot{0} \\
\dot{0}\end{array}$ & $\begin{array}{l}\text { o } \\
\text { it } \\
\dot{0} \\
\dot{0}\end{array}$ & & $\overline{\overline{\underline{3}}}$ & 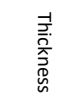 \\
\hline $\begin{array}{l}\omega \\
\text { U्ञ } \\
\dot{0}\end{array}$ & 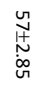 & 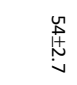 & 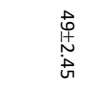 & 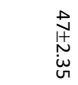 & 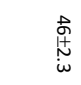 & $\begin{array}{l}\vec{\omega} \\
\text { 草 } \\
\dot{j}\end{array}$ & $\hat{ث}$ & & ळo & $\begin{array}{l}\text { o } \\
\text { o. } \\
\text { o. }\end{array}$ \\
\hline w & $\tilde{\sigma}$ & $w$ & $\stackrel{w}{v}$ & to & $\underset{\sim}{\sim}$ & $\underset{\omega}{\omega}$ & $\tilde{\iota}$ & & 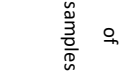 & 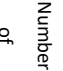 \\
\hline 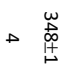 & $\begin{array}{l}0 \\
\stackrel{9}{0} \\
0 \\
0\end{array}$ & レ莙营 & 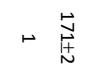 & ○䓛 & 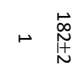 & • & $\backsim$ 兽 & & 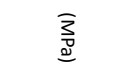 & a \\
\hline$\stackrel{\infty}{\stackrel{\infty}{~}}$ & gू & in & oै & $\infty$ & in & $\stackrel{\mathscr{\sim}}{\sim}$ & in & & & э \\
\hline 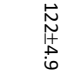 & 梷 & 疍 & 离 & 峐 & 兑 & 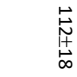 & $\begin{array}{l}\tilde{\tilde{N}} \\
\text { 莣 }\end{array}$ & & 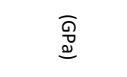 & $m$ \\
\hline$\stackrel{\stackrel{\check{I}}{ }}{ }$ & $\stackrel{\text { i }}{\underline{u}}$ & 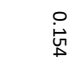 & 总 & 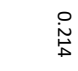 & 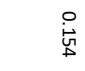 & 总 & 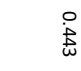 & & 蕜 & $\$$ \\
\hline 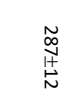 & $\begin{array}{l}\text { U. } \\
+\infty\end{array}$ & 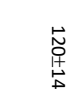 & 趋 & 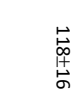 & 嵩 & 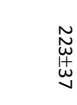 & 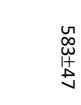 & & $\frac{\substack{\alpha \\
\frac{1}{3}}}{3}$ & $\therefore$ \\
\hline i & ' & ' & & 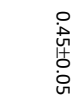 & 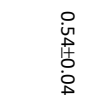 & 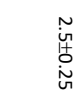 & 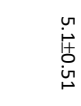 & & 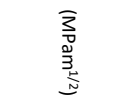 & 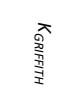 \\
\hline & & i & & 总 & 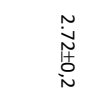 & 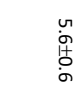 & 总总 & & 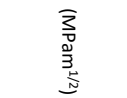 & $\bar{a}$ \\
\hline & ' & $\begin{array}{l}0 \\
0 \\
\text { 苗 }\end{array}$ & 荄 & & & & & & 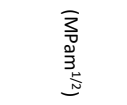 & त्र \\
\hline ' & ' & 竞 & $\begin{array}{l}\omega \\
\infty \\
\text { co } \\
\dot{w} \\
\infty \\
\infty\end{array}$ & & & & & & 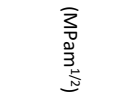 & 작 \\
\hline
\end{tabular}

Table III: Data from literature of ball-on-ring tests on NiO-3YSZ[8] and Ni-3YSZ[9] supported half-cells for comparison. The mentioned porosity refers to the support layer 


\begin{tabular}{|c|c|c|c|c|c|c|c|c|c|}
\hline \multicolumn{10}{|c|}{ Elastic and mechanical properties } \\
\hline \multirow[t]{3}{*}{ Sample name } & Material & Type of support & Porosity & Number of samples & $\sigma_{0}$ & $\mathrm{~m}$ & $\mathrm{E}$ & $V_{\text {eff }}$ & $\sigma_{0, \text { corr }}\left(V_{\text {eff }}=1 \mathrm{~mm}^{3}\right)$ \\
\hline & & HC: half-cell & (\%) & & (MPa) & & (GPa) & $\left(\mathrm{mm}^{3}\right)$ & \\
\hline & \multicolumn{3}{|c|}{ AS: anode support } & & & & & & \\
\hline Red600C & $\mathrm{Ni}-3 Y S Z$ & $\mathrm{HC}$ & 30 & 35 & 318 & 9.98 & 83 & 0.04 & 313 \\
\hline$[9][13]$ & & & & & & & & & \\
\hline Red1000C & $\mathrm{Ni}-3 Y S Z$ & $\mathrm{HC}$ & 30 & 35 & 361 & 11.01 & 83 & 0.04 & 356 \\
\hline$[9][13]$ & & & & & & & & & \\
\hline SPRT1 HT TM [8] & NiO-3YSZ & $\mathrm{HC}$ & 6.8 & - & 508 & 11.3 & 167 & 0.041 & 383 \\
\hline SPRT1 HT LM[8] & NiO-3YSZ & $\mathrm{HC}$ & 13.7 & - & 339 & 15.7 & 134 & 0.024 & 267 \\
\hline FTCT1 HT MM[8] & $\mathrm{NiO}-3 \mathrm{YSZ}$ & $\mathrm{HC}$ & 11.9 & - & 456 & 9.8 & 142 & 0.051 & 337 \\
\hline FTCT1 LT MM [8] & NiO-3YSZ & $\mathrm{HC}$ & 17.4 & - & 243 & 8.9 & 119 & 0.006 & 137 \\
\hline FTCT2 LT TM1[8] & NiO-3YSZ & $\mathrm{HC}$ & 9 & - & 600 & 10.4 & 156 & 0.045 & 445 \\
\hline FTCT2 LT TM2[8] & NiO-3YSZ & $\mathrm{HC}$ & 7 & - & 609 & 10.9 & 166 & 0.043 & 456 \\
\hline FTCT2 HT TM[8] & NiO-3YSZ & $\mathrm{HC}$ & 4.2 & - & 758 & 9.6 & 181 & 0.054 & 559 \\
\hline SPR CF HT TM[8] & NiO-3YSZ & $\mathrm{HC}$ & 12.6 & - & 395 & 12.4 & 139 & 0.024 & 292 \\
\hline
\end{tabular}

\section{Biaxial tensile strength}

The results for the biaxial tensile strength tests measured at room temperature using the ball-on-ring method are summarized in Table II and plotted in Fig. 3. The calculated Weibull strength $\left(\sigma_{0}\right)$, Weibull modulus $(m)$ and the effective volume $\left(V_{\text {eff }}\right)$ for the different samples were determined as described in refs $[8,31]$

The Weibull strength of the new 3YSZ anode supports (BB) is compared in Fig. 3 with data on the conventional NiO-3YSZ half-cells $(\Delta)$ and data on the conventional $\mathrm{Ni}-3 Y S Z$ supported cell (Red600C and Red1000C) reported in literature in ref. [8], [9] and [13] respectively and obtained using similar test methodology. Fig. 3 also reports a new experimental value obtained in this investigation (2G -DTU) 
corresponding to a Ni-3YSZ anode support. The test volume of $0.04 \mathrm{~mm}^{3}$ for Red600C and Red1000C is not mentioned in [9], but it has been calculated in this work. The Weibull strengths of all the tested BB supports and the values taken from literature were scaled to the same effective volume $\left(V_{\text {eff }}=1 \mathrm{~mm}^{3}\right)$ using the conventional scaling law (see e.g. $[8,57])$. All these data are summarized in Table II and III.

The data in Fig. 3 and Table II shows a clear decrease in Weibull strength of 3YSZ with increasing porosity, as expected [6-10]. The maximum Weibull strength value of $676 \mathrm{MPa}$ was found for the denser sample (BB05), while for the sample with $47 \%$ porosity and identical composition (BB07), the Weibull strength value was $182 \mathrm{MPa}$. Furthermore, considering the four set of samples with similar porosities (BB07,BB08, BB09, BB10 : 46-54\%), the lowest Weibull strength was observed for the $47 \%$ porous samples (BB09), which was made with the addition of YSZ fibres.

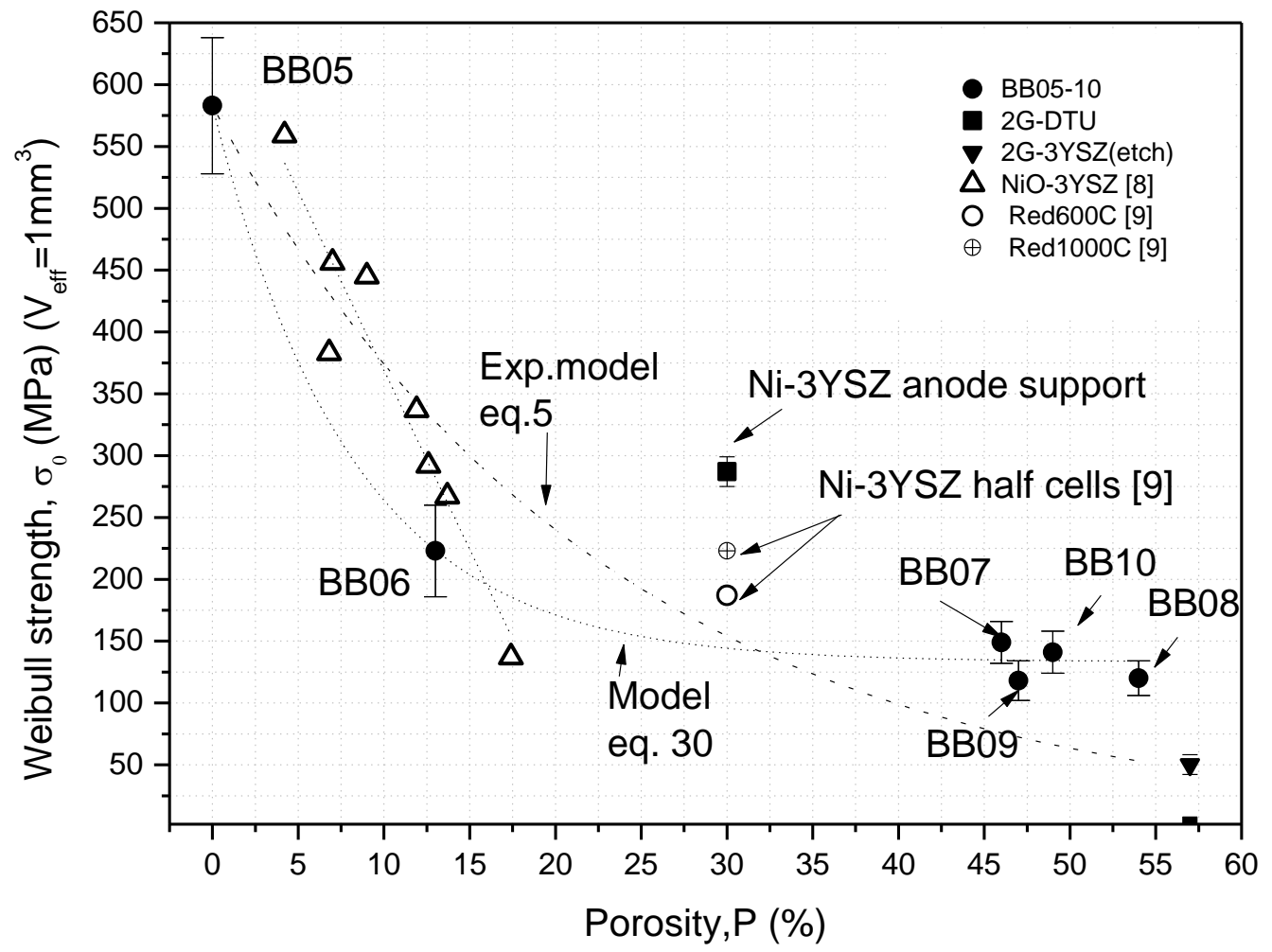

Fig. 3: Variation of the Weibull strength as function of porosity for 3YSZ support and comparison with $\mathrm{Ni} / \mathrm{NiO}-3$ YSZ trends. Data for NiO-3YSZ[8] and Ni-3YSZ (Red600/1000 ${ }^{\circ} \mathrm{C}$ ) [9] was taken from literature (filled symbols were used for the present work data) 
Fig. 3 shows that the Weibull strength of 3YSZ supports (BB) decreases fast in the $0-15 \%$ porosity range, then the dependence on porosity decreases up to a porosity level of $50 \%$. For the sample of Ni-3YSZ, where $\mathrm{Ni}$ has been removed by etching (2G-3YSZ, etch), the porosity rises to $56 \%$ and the strength decreases well below the value expected for 3YSZ from extrapolating the trend of the pure YSZ samples to this porosity level (see Fig. 3).

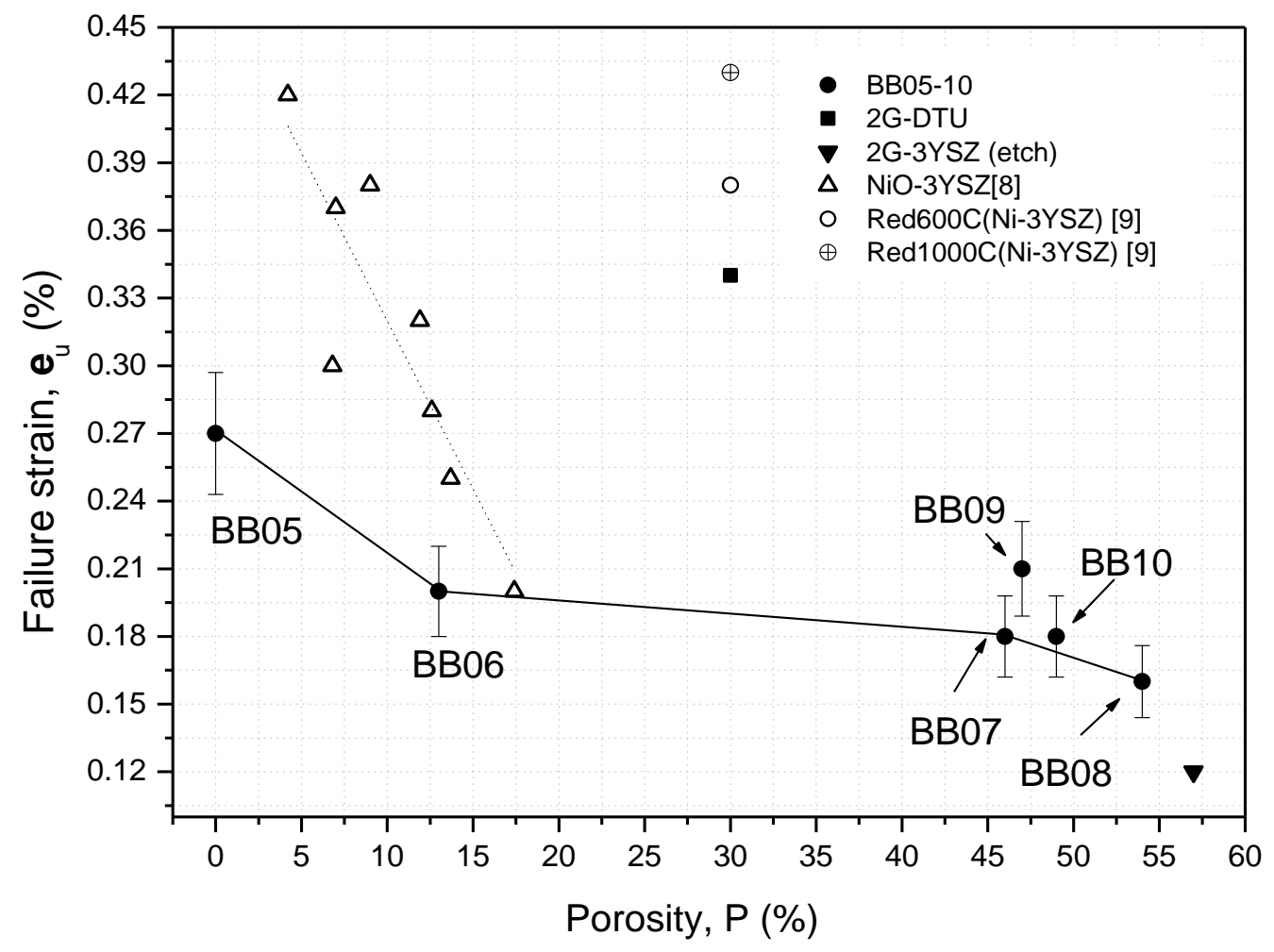

Fig. 4: Failure strain vs. porosity for 3YSZ support and comparison with Ni/NiO- 3YSZ trends. Data for NiO-3YSZ [8] and Ni-3YSZ (Reduced at $600 / 1000^{\circ} \mathrm{C}$ ) [9] was taken from literature (filled symbols are used for the data of the present work)

Fig. 4 shows the failure strain as function of porosity. The failure strain decreases with increasing porosity for the BB samples. In the low porosity range $(0-15 \%)$ the decrease is stronger than above $15 \%$. 


\section{R-curve behaviour and sub-critical crack growth in porous 3YSZ bodies}

\section{R-curve behaviour}

The variation of fracture toughness and SCCG as function of porosity for 3YSZ supports was determined by the double cantilever beam technique following the procedure described in the Experimental methods section and in ref. $[11,12,53]$.

In Fig. 5 the crack resistance versus crack extension is plotted for the investigated samples. As seen in Fig. 5 a distinct R-curve behaviour is found in the dense 3YSZ specimens (BB05), in BB06 (13\% porosity), BB07 (46\% p.), and for BB09 (47\%p., 10wt\% of 3YSZ fibres). R-curve behaviour was not observed in the porous BB08 and BB10 samples, which displayed sub-critical crack growth.

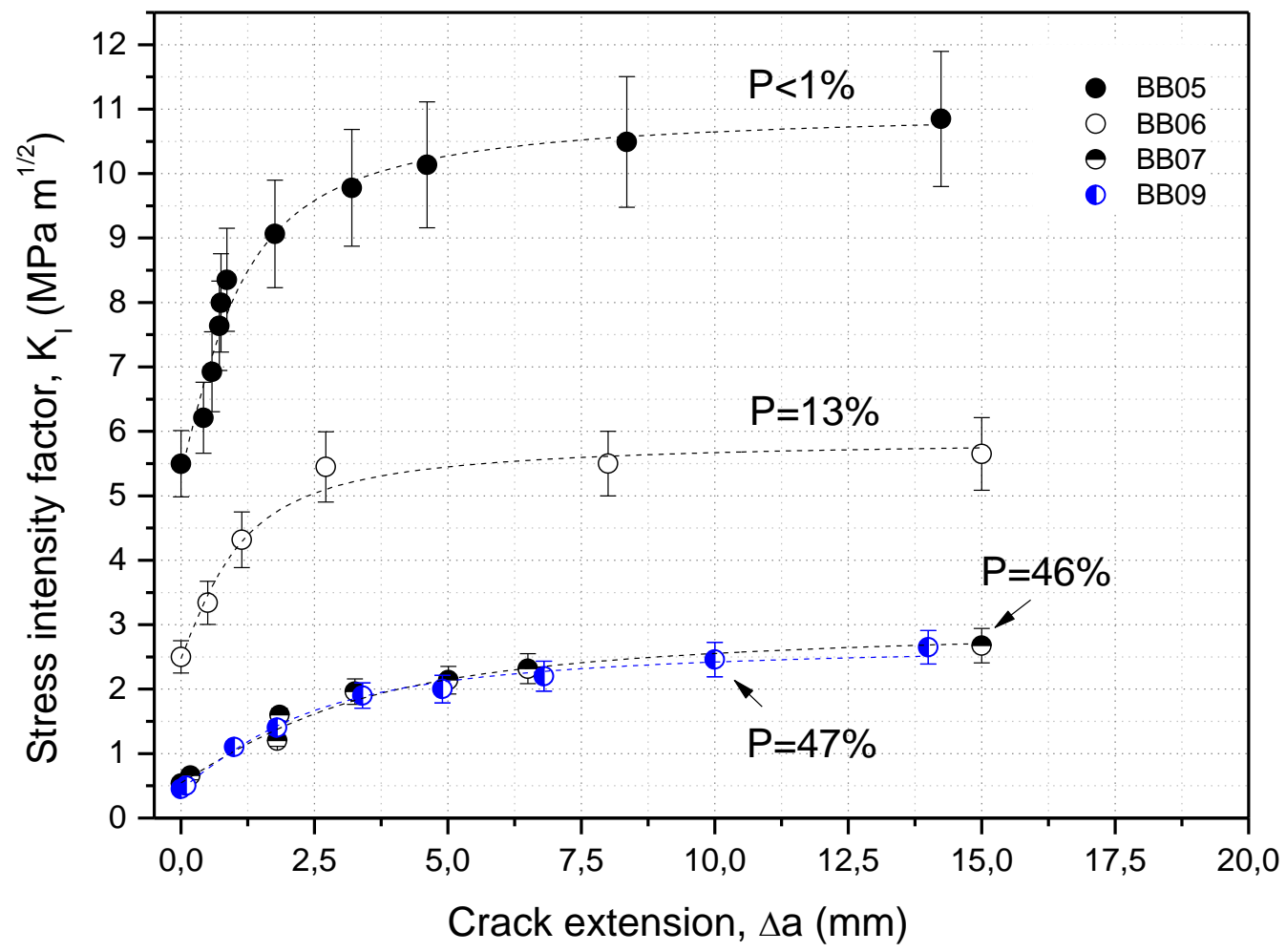

Fig. 5: R-curve behaviour of 3YSZ samples with different porosity (P) values

\section{Subcritical crack growth}


Fig. 6 shows the SCCG velocity plotted against the Mode I stress intensity factor calculated from Eq. 19 obtained for BB10 and BB08 supports. Data of dense 8YSZ [10] and NiO-3YSZ [12] taken from literature are also included in Fig. 6 for comparison. The gap between $K_{I C}^{f}$ and $K_{I C}^{a}$ seems to increase for increasing porosities, as indicated by the lower slopes in Fig. 6 .

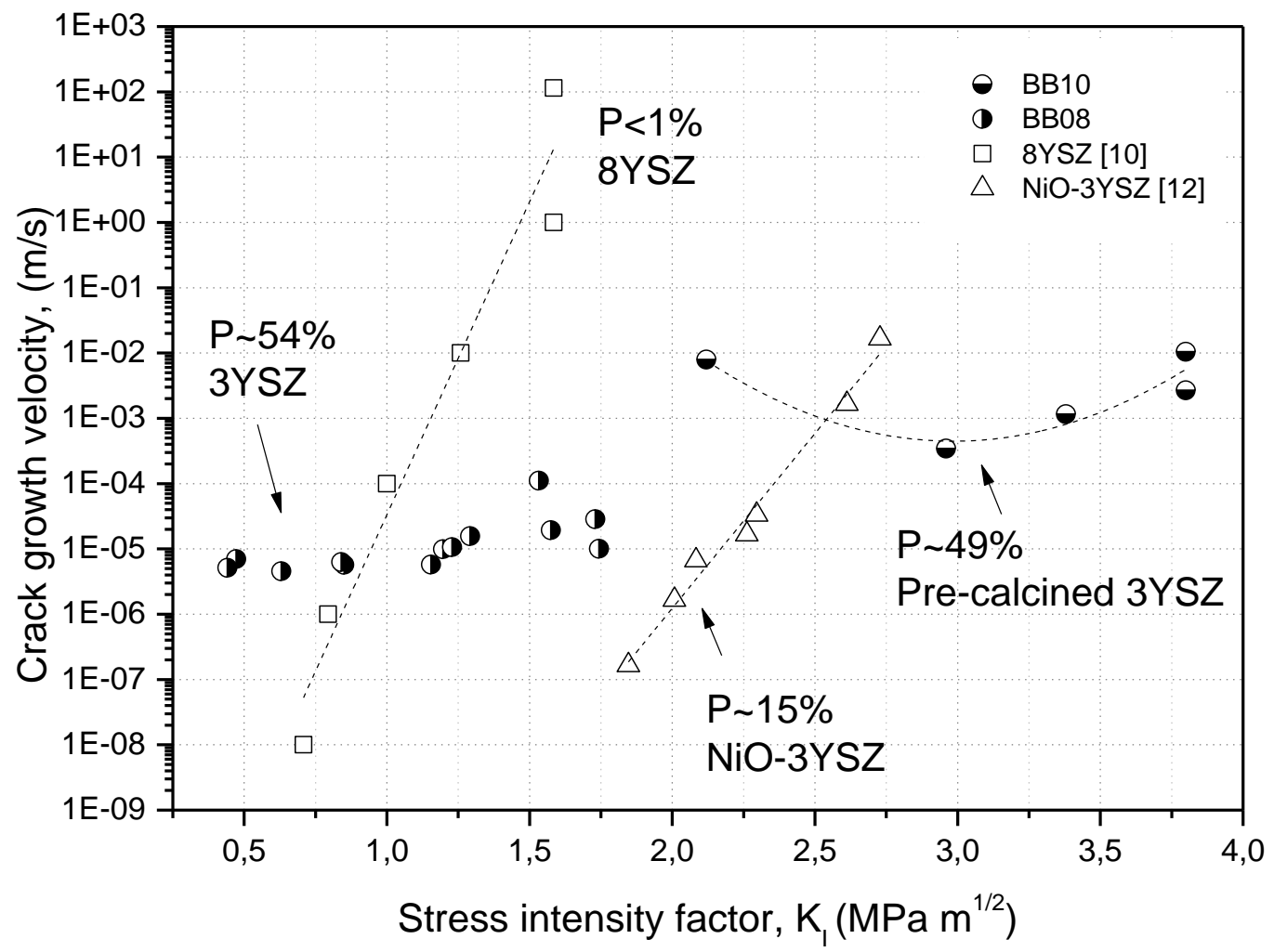

Fig. 6: Average crack growth rate as function of applied stress intensity factor (open symbols correspond to literature data)

\section{Discussion}

\section{A. Elastic modulus}

From the data in Fig. 2 it is possible to compare the elastic modulus of NiO-3YSZ half-cells $(\Delta)$ to the corresponding Ni-3YSZ half-cell after reduction (label; Red600C). The decrease in elastic modulus seems dominated by the associated increase in porosity after the reduction (from $13 \%$ to $30 \%$ ) since the $\mathrm{Ni}$ - 
3YSZ point falls on the extrapolated trend from the NiO-3YSZ data. This later is in agreement with the results from ref. [58].

\section{Elastic modulus-porosity correlation}

Table IV reports the parameters $\left(b_{E}\right.$ and $\left.E_{0}\right)$ of the models used for the fitting of experimental data and the correlation coefficients $\left(\mathrm{R}^{2}\right)$ for the 3YSZ samples. BB09 and BB10 data were not included in the fitting due to the different raw materials employed in the original slurries. Assuming $E_{0}=217 \mathrm{GPa}$ from ref.[8] ( $E$ of BB05 with porosity $<1 \%=214 \mathrm{GPa}$, see Table II) then the only adjustable fitting parameter used was $b_{E}$, see Eq.10.

It was found that standard models (e.g. CSM and exponential) predict the elastic modulus variation as function of porosity with good correlation coefficients in the 0-30\% porosity range, with $\mathrm{R}^{2}$ in the range of 0.9-0.92 (fitting curves are not reported in the paper), for both 3YSZ (BB samples) and NiO-3YSZ ( $\Delta$ ) data. This is in agreement with literature, since it has been demonstrated $[7,8,10]$ that both the exponential (Eq.11) and the composite sphere model (Eq. 10) can give good fitting correlations for both NiO-3YSZ [6,8] and also for 3YSZ [7] in the 0 to 30\% porosity range (see Table IV). However, when the fitting was performed for the complete range of porosity, e.g. for the BB samples investigated here (0$54 \%$ ), both models showed poor agreement yielding $R^{2}$ values of 0.8 and 0.67 , for the exponential and the CSM model, respectively.

Fig. 2 shows the best fit curve obtained, corresponding to the exponential model (eq. 10). Whereas the model catches the overall trend, there are systematic differences between the NiO/YSZ and the pure YSZ samples and variations between the back-bone-samples that are not caught by the simple model $A$ decrease in goodness of fitting for increasing porosities has also been reported for other materials by different authors $[15,16]$.

Table IV: Exponential and CSM correlations for Young's modulus vs. porosity of 3YSZ samples and available data in literature for 3YSZ material [7]

\begin{tabular}{|c|c|c|}
\hline \multirow[t]{3}{*}{ Model } & \multicolumn{2}{|c|}{ Material } \\
\hline & $3 Y S z[7]$ & 3YSZ (BB samples) \\
\hline & Porosity range (0-10\%) & Porosity range (0-54\%) \\
\hline
\end{tabular}




\begin{tabular}{cccc}
\hline Exponential & $E_{0}$ (GPa) & 217.46 & $217 \pm 20$ \\
& $b_{E}$ & 3.01 & 2.44 \\
& $R^{2}$ & 0.92 & 0.8 \\
\hline CSM & $E_{0}(\mathrm{GPa})$ & 217.78 & $217 \pm 20$ \\
& $b_{E}$ & 0.99 & -0.15 \\
& $R^{2}$ & 0.88 & 0.68 \\
\hline
\end{tabular}

\section{B. Tensile strength}

The comparison of the porous backbones (BB07, 08, 09, 10) and the Ni-3YSZ support (2G-DTU) and Ni3YSZ supported half-cells (Red600C and Red1000C) (p. 30\%) show that they have similar Weibull modulus ( 8-10). The results reported in Table II (last column, $\sigma_{f c o r r}$ ) show that the corrected Weibull strengths of the porous backbones $(\mathrm{BB} 07,08,09,10)$ are in the range of $120-149 \mathrm{MPa}$. These values are significantly lower than those of Ni-3YSZ support samples (2G-DTU, $287 \mathrm{MPa}$ ) and half-cells (e.g. Red600C, $312 \mathrm{MPa}$ and Red1000C, $356 \mathrm{MPa}$ ) for similar $\mathrm{V}_{\text {eff }}$. The major contributor to the decrease in Weibull strength is the higher porosity of the investigated system (50\% against $30 \%$ ). However, if we compare in Fig. 3 the values of Red600C, Red1000C, 2G-DTU with the BB fitting trend, it is clear that the values of Red600C, Red1000C, 2G-DTU are also higher than the corresponding values in the BB trend at the same porosity (30\%). In the case of Ni-3YSZ (2G-DTU) composites, the higher strength is probably due to the beneficial effect of the ductile Ni phase, as other authors have also pointed out [6].

It is also interesting to compare the strength of NiO-3YSZ half-cells $(\Delta)$ with the corresponding Ni-3YSZ cermet after reduction (Red600C, Red1000C). Despite the increase of porosity from approximately $13 \%$ to $30 \%$, the Weibull strength does not decrease as much as expected if only the porosity was increased of the NiO-3SYSZ samples. This latter is probably again due to the beneficial effect of the ductile Ni on the strength of the composite. In fact, ductile particles can cause R-curve behaviour due to crack bridging in Ni-3YSZ cermets, increasing consequently the strength. Crack bridging by Ni-metal bridges was found in Ni-3YSZ cermets in ref. [6] but the R-curve behaviour was not investigated .

For the samples of Ni-3YSZ, where Ni has been removed by etching (2G-3YSZ, etch) the porosity increases to $56 \%$ and the strength decreases well below the corresponding extrapolated value for $3 Y S Z$ 
at this porosity (see Fig. 3). This behaviour could be due to pore interactions and intersections that may occur at this high porosity level [41] and also that the shape of the pores change on etching becoming less round.

It was found that the use 3YSZ fibres have no any beneficial effect in on the strength. In fact, the strength of BB09 is the lowest for all the samples with similar porosities (47-54\%). A possible explanation can be found looking at the SEM image of BB09 reproduced in Fig. 1. Inhomogeneity's are present in the microstructure due to poor fibre distribution, and this seems to lead to an accumulation of pores and defects and consequently to the formation of longer defects that can act as initial flaws during fracture.

\section{Strength-porosity correlation}

Fitting of the experimental strength data of the BB samples has been carried out using the exponential model (Eq. 12). Results are reported in Table V. As can be seen in Fig. 3 for NiO-3YSZ and 3YSZ (BB), the decrease in strength with porosity in the $0-30 \%$ porosity range is more pronounced than predicted by the exponential fitting curve (eq.12). This can be due to a decreased influence of transformation toughening with porosity, as reported in ref. [8] for NiO-3YSZ. From this, one single model covering all the porosity range (0-50\%) inevitably provides inaccurate fitting. Improved correlations coefficients can be obtained dividing these models in two parts, one suitable in the range from 0 to 30 and the other one in the range from $25-50 \%$.

Three new models are proposed here to take into account not only the effect of variations in Young's modulus, but also the decreasing impact of transformation toughening with increasing porosity.

The first model corresponds to a modified exponential model defined by the following equation:

$\sigma=\sigma_{0} e^{\left(-b_{\sigma} P\right)}-k P$

where the constant $k$ is obtained by fitting. The modified SCE model has the expression:

$\sigma=\sigma_{0}(1-\mathrm{P})^{b_{\sigma}}+c P$

where the constant $c$ is also obtained by fitting.

A third model is proposed based on the following equation: 
$\sigma=\mathrm{yo}+A e^{\left(-b_{\sigma} P\right)}$

where yo and $A$ and $b_{\sigma}$ are fitting constants.

Table $V$ shows the correlation coefficients for the standard minimum contact area and stress concentration effects (SCE) models and also for the corrected models here proposed for strength values corresponding to at an $V_{\text {eff }}=1 \mathrm{~mm}^{3}$. The improved fit is evident when observing the correlations coefficients in Table V corresponding to the modelling equations 28, 29 and 30 in comparison to the standard models of eq. 12 and 13 for the same set of experimental data. We assume $\sigma_{0}=\sigma_{B B 05}(583$ $\mathrm{MPa}$ ) for 3 YSZ samples and consequently the only adjustable fitting parameter used was $b_{\sigma}$ for the exponential, SCE and CSM models and $b_{\sigma}$ and the fitting constants for the modified fitting models (A, y0, $\mathrm{c}$ and $\mathrm{k})$. Table $\mathrm{V}$ also includes the fitting results for the experimental data of NiO-3YSZ [8].

Table V: Exponential, SCE, CSM and modified exponential and SCE correlations for strength vs. porosity of 3YSZ samples and available data in literature for 3YSZ and NiO-3YSZ composites

\begin{tabular}{|c|c|c|c|}
\hline \multicolumn{2}{|l|}{ Model } & \multicolumn{2}{|c|}{ Material } \\
\hline & & NiO-3YSZ[8] & 3YSZ (BB samples) \\
\hline & & $\begin{array}{c}\text { Porosity range } \\
\text { (0-18\%) }\end{array}$ & $\begin{array}{l}\text { Porosity range } \\
\text { (0-54\%) }\end{array}$ \\
\hline Exponential & $\sigma_{0}$ & 776 & $583 \pm 47$ \\
\hline \multirow[t]{2}{*}{ (eq. 12) } & $b_{\sigma}$ & 7.9 & 3.81 \\
\hline & $R^{2}$ & 0.88 & 0.85 \\
\hline SCE & $\sigma_{0}$ & 753 & 583 \\
\hline \multirow[t]{2}{*}{ (eq. 13) } & $b_{\sigma}$ & 7.1 & 2.87 \\
\hline & $R^{2}$ & 0.89 & 0.78 \\
\hline
\end{tabular}




\begin{tabular}{|c|c|c|c|}
\hline \multirow[t]{3}{*}{ CSM } & $\sigma_{0}$ & 887 & $583 \pm 47$ \\
\hline & $b_{\sigma}$ & 10.7 & 2.72 \\
\hline & $R^{2}$ & 0.87 & 0.84 \\
\hline \multirow{4}{*}{$\begin{array}{c}\text { Exp-modified } \\
(\text { Eq.28) }\end{array}$} & $\sigma_{0}$ & 658 & $583 \pm 47$ \\
\hline & $b_{\sigma}$ & $5.00 \mathrm{E}-05$ & 8.6 \\
\hline & $k$ & 2892 & -270 \\
\hline & $R^{2}$ & 0.91 & 0.99 \\
\hline \multirow{4}{*}{$\begin{array}{l}\text { SCE-modified } \\
\text { (Eq. 29) }\end{array}$} & $\sigma_{0}$ & 657 & $583 \pm 47$ \\
\hline & $b_{\sigma}$ & 0.48 & 8.1 \\
\hline & $c$ & -2557 & 284 \\
\hline & $R^{2}$ & 0.91 & 0.99 \\
\hline \multirow{4}{*}{$\begin{array}{l}\text { Exp. model of } \\
\text { (Eq. 30) }\end{array}$} & $y_{0}$ & 1281 & 143 \\
\hline & $A$ & -663 & 438 \\
\hline & $b_{\sigma}$ & $-1 / 0.32$ & -13.23 \\
\hline & $R^{2}$ & 0.92 & 0.99 \\
\hline \multirow[t]{2}{*}{ Linear model } & $A$ & 658 & - \\
\hline & $b$ & -2892 & - \\
\hline
\end{tabular}


It is interesting, as seen in Table $\mathrm{V}$, that the fitting of NiO-3YSZ data from ref. [8] with a linear trend give a correlation coefficient of $0.96 \%$, higher than the correlation obtained for the exponential models. This could indicate that the dominating effect in the $0-30 \%$ porosity range is the transformation toughening decrease represented by the linear component in Eq. 29-30. A suggestion to support why the transformation toughening decrease can be represented by a linear decreasing trend is presented below.

\section{R-curve behaviour}

Clear R-curve behaviour was observed for four of the backbone structures (Fig. 5). The degree of toughening decreased with increasing porosity as indicated by the lower $\Delta K_{R_{S S}}$ obtained for the most porous samples (see Fig. 5). The toughening mechanism stems from a local volume expansion in the material. However, the initial process zone at the tip of a stationary crack has no net effect on the toughness of the material before the material points begin to unload [46]. Indeed, it is the unloading (non-reversible stress-strain history) in the wake of transformed material behind the crack tip that leads to an increase in toughness.

When some of the material is removed and replaced by porosity (as is the net effect of increasing the porosity in the sample), a reduction in the volume fraction of the transforming particles $\left(V_{f}\right)$ and also a decrease in the effective Young's modulus $(E)$ is expected. On the other hand, an increase in the width of the transformation zone $(d)$ could be expected due to the decrease in Young's modulus $(E)$ of the material with porosity [59]. In fact, McMeeking [22] has pointed out that $E$ plays an important role in determining the effectiveness of the dilational strain produced by the zirconia phase on the matrix, i.e. the back stress imposed on the transformation by the high $E$, effectively lowers the transformation efficiency, thus reducing $d$. All in all, following eq. 20, the effects of decreasing $E$ and $V_{f}$ dominates over the increase of $d$ with increasing porosity, leading to the observed decrease of $\Delta K_{R_{S S}}$. It is also evident from Fig. 5 that the crack-initiation toughness $K_{R_{0}}$ decreases with increasing porosity. In the next section, a discussion on the variation $\Delta K_{R_{S S}}$ and $K_{R_{0}}$ with porosity and its implications on strength is presented. 
The R-curve behaviour observed in BB09 is similar that observed in the BB07 sample (the $K_{R}$ values of BB09 are identical to the values obtained for BB07 within one standard deviation). Hence, there is no beneficial effect of the fibres, which were a priori hoped to add a crack bridging improvement on top of the transformation toughening effect.

In Fig. 5, the dashed lines represent "the best fit" of the arctan function (Equation 22). Table VI reports the fitting parameters obtained with the models of Evans (eq. 22) [47] and Shetty et al. (eq. 23) [48]. Both models fit the experimental data satisfactorily, as the high $\mathrm{R}^{2}$ values demonstrate. It is worthwhile to remark that the values of $d$ obtained from the fitting with the Evans' model are in good agreement with the width of the transformation zone observed by SEM microscopy and determined by Raman spectroscopy (data not reported here). For the dense sample (BB05) a value of $1 \mu \mathrm{m}$ was calculated from fitting (Table VI) and Raman spectroscopy while for the highly porous samples (BB07-BB09), values between 2-4 $\mu \mathrm{m}$ were determined.

If we consider the values reported in Table III of ref. [24] for Y-TZP, where $e_{T}=0.05, v=0.3, \eta=0.214 /(1$ $v$ ) and for $V_{f}=1$ and $d=1-1.2 \mu \mathrm{m}$, and considering that $E=214 \mathrm{GPa}$ for BB05 then the calculated $\Delta K_{R_{S S}}-$ value is; $\Delta K_{R_{S S}} \sim 5 \mathrm{MPam}^{1 / 2}$. This result is consistent with the experimental results reported here. In fact, in Table $\mathrm{V}$ and if we consider the values obtained by fitting with the model of Shetty et al., $\Delta K_{R_{S S}}=$ $K_{R_{S S}}-\Delta K_{S S}=5.17 \mathrm{MPam}^{1 / 2}$. This value is also consistent with $K_{R_{0}}$ and $\Delta K_{R_{S S}}$ reported in ref. [24] and in ref. [60] for Y-TZP.

Table VI: Parameters of the models of Evans (eq. 22) [47], Shetty et al. (eq. 23) [48] and Heuer (eq. $26,27)$, obtained by fitting the experimental data

\begin{tabular}{c|c|c|c|c|c|c|c|c|c|c|c|c}
\hline \multicolumn{5}{c|}{ Evans (eq. 22) } & \multicolumn{3}{c|}{ Shetty et al. (eq. 23) } & \multicolumn{3}{c}{ Heuer et al. (eq. 26,27) } \\
\hline & $K_{R_{0}}$ & $K_{0}$ & $d$ & $\mathrm{R}^{2}$ & $\mathrm{~K}_{\mathrm{R}_{\mathrm{SS}}}$ & $K_{R_{0}}$ & $\lambda$ & $\mathrm{R}^{2}$ & $a_{0}$ & $\Delta a_{f}$ & $\sigma_{f p}$ & $\Delta K_{\Delta a_{f}}$ \\
& $\left(\mathrm{MPam}^{1 / 2}\right)$ & $\left(\mathrm{MPam}^{1 / 2}\right)$ & $(\mu \mathrm{m})$ & & $\left(\mathrm{MPam}^{1 / 2}\right)$ & $\left(\mathrm{MPam}^{1 / 2}\right)$ & $(\mu \mathrm{m})$ & & $(\mu \mathrm{m})$ & $(\mu \mathrm{m})$ & $(\mathrm{MPa})$ & $\mathrm{MPa} \sqrt{\mathrm{m}}$ \\
\hline BB05 & 5.33 & 3.62 & 0.97 & 0.96 & 10.52 & 5.35 & 1.36 & 0.95 & 60 & 8.6 & 583 & 0.47 \\
\hline BB06 & 2.47 & 2.17 & 1.01 & 0.98 & 5.63 & 2.46 & 1.41 & 0.99 & 90 & 15 & 272 & 0.88 \\
\hline BB07 & 0.54 & 1.58 & 3.11 & 0.96 & 2.72 & 0.54 & 3.73 & 0.95 & 150 & 61 & 132 & 1.85 \\
\hline
\end{tabular}




\begin{tabular}{l|l|l|l|l|l|l|l|l|l|l|l|l}
\hline BВ09 & 0.45 & 1.46 & 2.27 & 0.99 & 2.5 & 0.44 & 2.85 & 0.99 & 170 & 65 & 118 & 1.62 \\
\hline
\end{tabular}

\section{Strength-fracture toughness correlation}

The analysis of R-curves can lead to the assessment of the strength of materials, as explained above in the Fracture strength-R-curve correlation paragraphs of the Theory section. Knowing the initial flaw sizes $\left(\mathrm{a}_{0}\right)$, it is possible to predict the instability crack extension $\left(\Delta a_{f}\right)$ and the strength $\left(\sigma_{f p}\right)$ by simultaneously solving eq. 24 and 25 . This has been done by different authors, for example by Heuer et al. [52] leading to eq. 26 and 27.

We use this approach as follows:

As an example, for BB05, inserting $\mathrm{a}_{0}=60 \mu \mathrm{m}$ and $\mathrm{d}=0.97 \mu \mathrm{m}$ (Table IV) into eq. (26) $\Delta \mathrm{a}_{\mathrm{f}}=8.6 \mu \mathrm{m}$ is obtained. Inserting $K_{R_{0}}=5.35 \mathrm{MPa} \sqrt{\mathrm{m}}$ (TableIV) and $\Delta K_{\Delta a_{f}}=0.47 \mathrm{MPa} \sqrt{\mathrm{m}}$ (Table IV) in eq. (27), $\sigma_{\mathrm{fp}}=583 \mathrm{MPa}$ is obtained. The obtained values of strength are thus $583 \mathrm{MPa}, 272 \mathrm{MPa}, 132 \mathrm{MPa}$ and 118 for BB05, BB06, BB07 and BB09, respectively (Table VI).

Some of the estimated strengths fits very well with those obtained experimentally by the ball-on-ring method (BB05 and BB09) (see Table II for comparison), while others differ (BB06 and BB07) (18\% and $13 \%$ respectively). We believe that this discrepancy is because of the lack of experimental points at the beginning of the R-curve, which could lead to misrepresentation of the initial steepness of the curve, as other authors have also pointed out [61]. In fact, the first part of the R-curve is not accurately measured in the present study. The first experimental points are obtained after a crack extension in the order of 100-200 $\mu \mathrm{m}$ (see Fig. 5), while, as can be seen in Table VI, the instability crack extensions are lower than $100 \mu \mathrm{m}$ for all the investigated materials. Thus, future work should be directed to study the shape of the R-curve for small crack extensions ( 0 to $200 \mu \mathrm{m}$ ). This might be possible introducing a procedure involving a heat-treatment after crack initiation to reverse the $t \rightarrow m$ transformation associated with the initial crack extension $[18,49]$.

Table VI summarizes the values of the instability crack extension and the strength determined by the above-mentioned approach. 


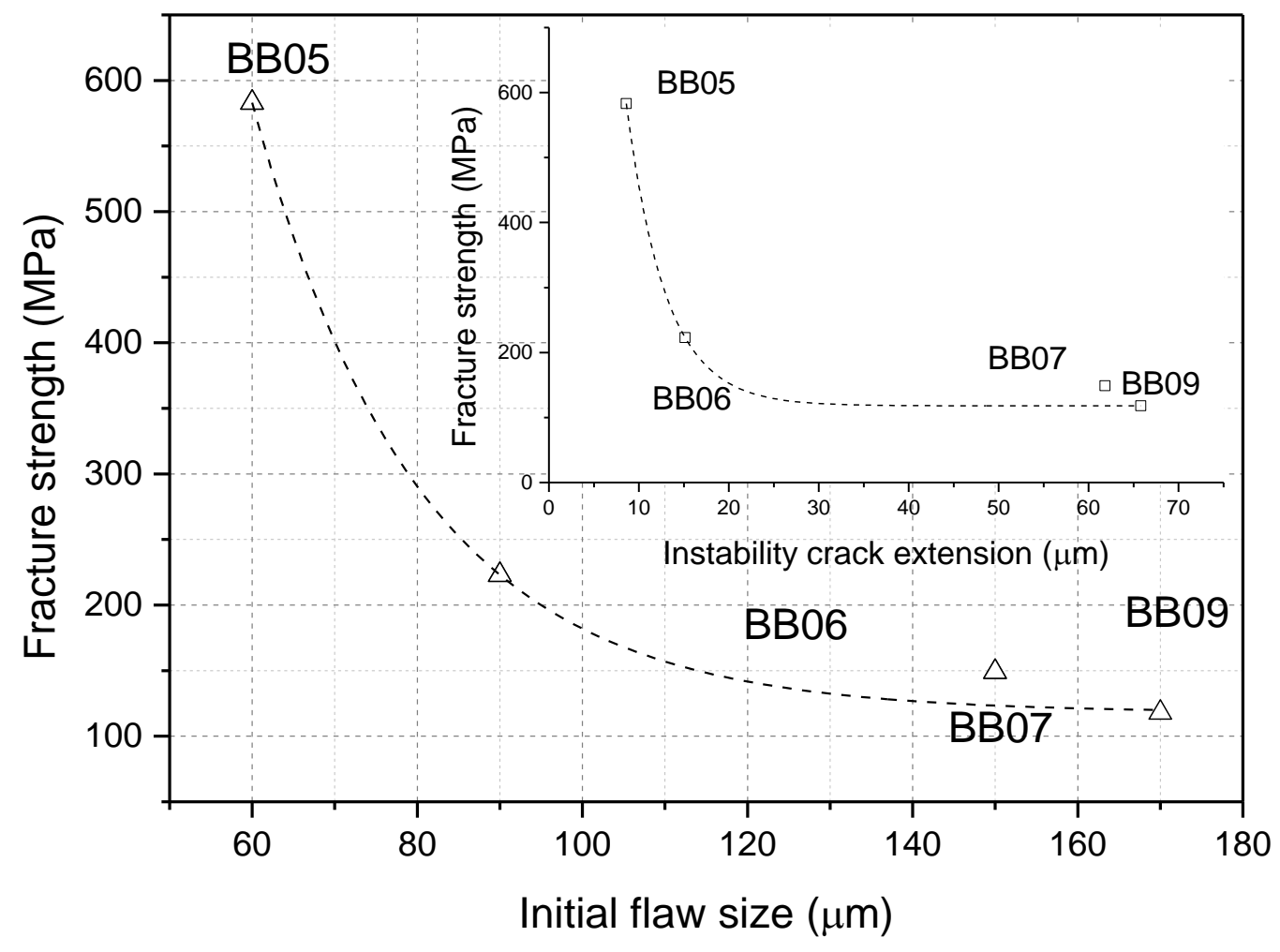

Fig. 7: Initial flaw length and instability crack extension vs. strength from the Heuer model (dash lines are curve fittings)

The obtained values are in agreement with those reported in literature, e.g. in ref. [62] for MgO-PSZ samples, starting flaw sizes of 70-185 $\mu \mathrm{m}$ with instability crack extension from 0-65 $\mu \mathrm{m}$ are reported, for materials with fracture strengths in the range of 475-700 MPa.

From the analysis of the values obtained with Heuer's models (eq. 26,27 ) and reported in Table VI, it can be seen that the denser samples, BB05, with a fracture strength of $583 \mathrm{MPa}\left(\mathrm{V}_{\text {eff }}=1 \mathrm{~mm}^{3}\right)$, derives from a material with a $10.5 \mathrm{MPam}^{1 / 2}$ plateau toughness $\left(\mathrm{K}_{\mathrm{R}_{\mathrm{SS}}}\right)$. It failed from a $\sim 60 \mu \mathrm{m}$ flaw after a stable crack growth of $\sim 9 \mu \mathrm{m}$. The failure occurred at a $K_{R_{\Delta a_{f}}}=K_{R_{0}}+\Delta K_{\Delta a_{f}}=5.8 \mathrm{MPam}^{1 / 2}$.

BB06 (13\% porosity), had a plateau toughness of $5.63 \mathrm{MPam}^{1 / 2}$, a strength of $223 \mathrm{MPa}\left(\mathrm{V}_{\text {eff }}=1 \mathrm{~mm}^{3}\right)$, and failed at a $K_{R_{\Delta a_{f}}}$ of $3.6 \mathrm{MPam}^{1 / 2}$ from a starting flaw of $90 \mu \mathrm{m}$ after stable flaw growth of $15 \mu \mathrm{m}$. BB07 (46\% porosity), had a plateau toughness of $2.72 \mathrm{MPam}^{1 / 2}$ and a fracture strength of $149 \mathrm{MPa}\left(\mathrm{V}_{\text {eff }}=1\right.$ 
$\mathrm{mm}^{3}$ ). It failed at a $K_{R_{\Delta a_{f}}}$ of $2.3 \mathrm{MPam}^{1 / 2}$ from an initial flaw of $150 \mu \mathrm{m}$ after $61 \mu \mathrm{m}$ of stable crack growth.

BB09 (47\% p.) had a fracture strength of $118 \mathrm{MPa}\left(\mathrm{V}_{\mathrm{eff}}=1 \mathrm{~mm}^{3}\right)$. It failed at $K_{R_{\Delta a_{f}}}=2.2 \mathrm{MPam}^{1 / 2}$ from an initial flaw of $170 \mu \mathrm{m}$ after a stable crack growth of $65 \mu \mathrm{m}$. In the SEM images of BB09 in Fig. 1 a microstructural inhomogeneity created by a fibre of $30 \mu \mathrm{m}$ length is observed. These inhomogeneities can act as crack starters. An initial flaw size of $170 \mu \mathrm{m}$ is in agreement with the SEM observations and represents an acceptable mean value also regarding the fibre lengths. It is worthwhile to note that BB09, the sample showing the lowest strength is also the one showing the highest initial flaw size, as expected.

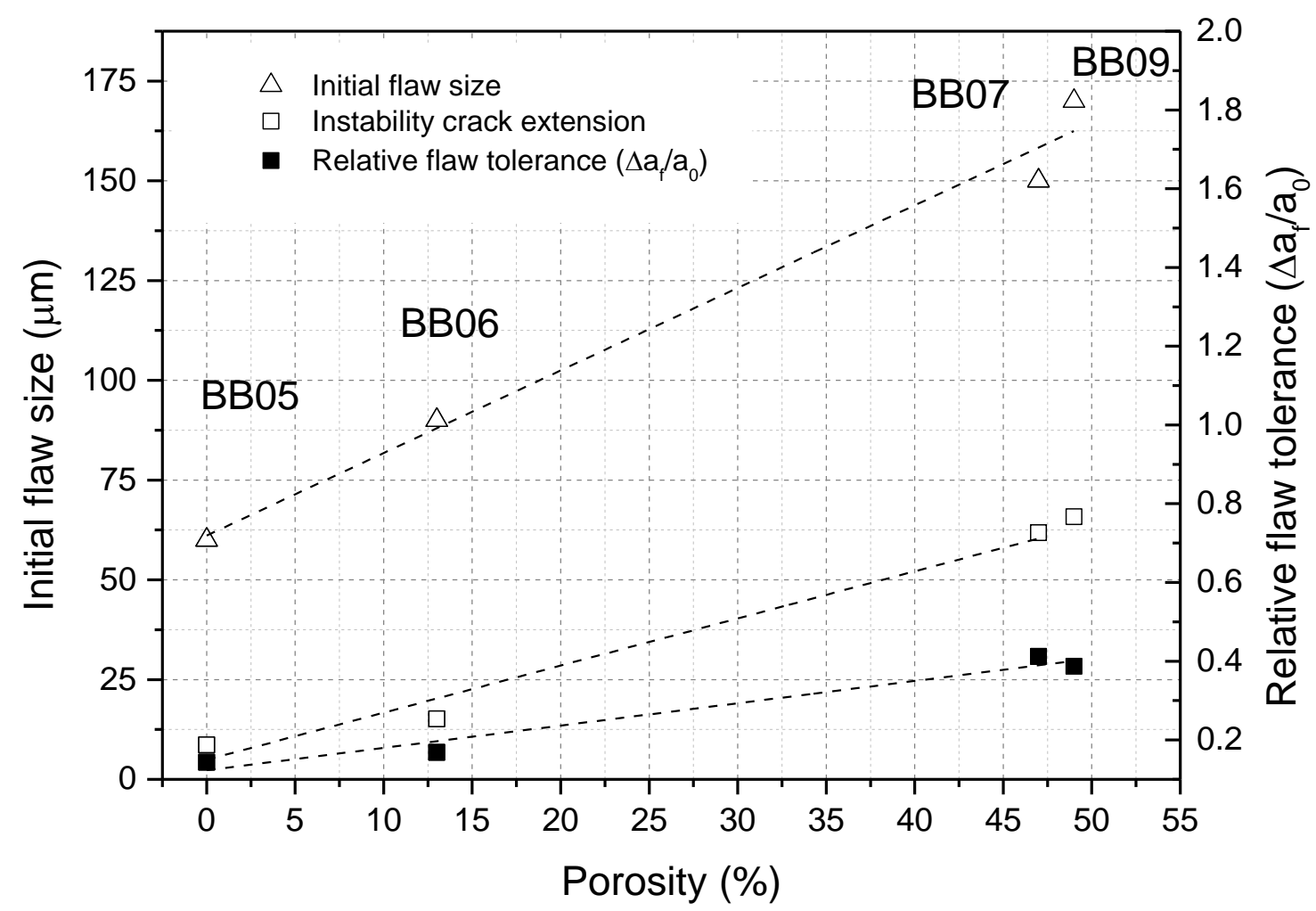

Fig. 8: Initial crack size and instability crack extension shown as a function of porosity. The dashed lines correspond to linear fittings of experimental data

These values of fracture strength for the different samples are plotted as a function of the initial flaw size and instability crack extension in Fig. 7. Additionally, the initial flaw size and instability crack extension are plotted as function of porosity in Fig. 8. Fig. 7 shows that the strength follows an 
exponential decay versus the initial flaw size (in agreement with ref. [52]) and the instability crack extension. In addition, Fig. 8 shows that both flaw sizes (initial flaw size and instability crack extension) increase for increasing porosity.

As mentioned above in the tensile strength discussion section, the steepest slope in the strength vs. porosity curve (Fig. 3) is found in the low porosity range, i.e. from BB05 to BB06; a porosity increase of $\sim 13 \%$ leads to a decrease in strength of $60 \%$, while, for BB06-BB07, a porosity decrease of 33\% yields a decrease in strength of $\sim 30 \%$. This steep slope in the strength-porosity correlation at the low porosity range is higher than the slope corresponding to a material without R-curve behaviour, e.g. for a porosity change of $15 \%$ (from 6 to 21\%) it is reported to have a decrease in strength of 30\% for NiO-8YSZ[6] $\left.\left(b_{\sigma} \sim 2.5\right)\right)$, as pointed out in [8]. This could suggest the presence of a critical porosity value $\left(P_{\text {crit }}\right)$ corresponding to a transition in the strength-porosity correlation. For porosities below the critical value, the strength decreases with the decreasing trend of an un-toughened porous ceramic plus the reduction in strength originated by the reduction of the transformation toughening effect. After this porosity threshold, strength is affected by the porosity increase, probably with the same law of a typical untoughened porous ceramic, since the incremental toughness has not anymore a net effect in the improvement of strength.

\section{E. Failure strain}

The decreasing trend of the failure strain of 3YSZsupports (BB) in the 0-15\% porosity range in Fig. 4 is due to the steeper slope of the strength-porosity curve (Fig. 3) compared to that of the elastic modulusporosity one $\left(b_{\sigma}=8>b_{E}=2\right)$ (Tables IV and V). As mentioned above, this steep slope of the strengthporosity curve in the low porosity range can be due to a decreased effect of transformation toughening. In ref. [6], the reported values of $b_{\sigma}$ for NiO-8YSZ and Ni-8YSZ are $2.58 \pm 0.34$ and $5.1 \pm 0.67$, respectively.

We think that the high value of $b_{\sigma}(8)$ found in this investigation for 3YSZ samples can be ascribed to the increase in strength yielded by the incremental toughness from transformation toughening (improvement by R-curve behaviour), which is also in agreement with ref. [8]. This is particularly important for the dense samples (BB05). It is worthwhile to point out that in ref. [6] the fracture toughness of Ni-8YSZ is higher than that of NiO-8YSZ $\left(\mathrm{K}_{\mathrm{ICO}}=7.52 \pm 0.93\right.$ for reduced material and $\mathrm{K}_{\mathrm{ICO}}=$ $2.54 \pm 0.38 \mathrm{MPam}^{1 / 2}$ for unreduced anode material). The higher fracture toughness value of the reduced cermet could indicate the presence of crack bridging phenomena giving rise to R-curve behaviour which is possibly the reason of the increased $b_{\sigma}(7.52)$. 
In the $20-50 \%$ porosity range the strain at failure is effectively constant reflecting that the elastic modulus and the strength scales similarly with porosity $\left(b_{\sigma}^{\sim}=b_{E}=2\right)$.

For porosities higher than $50 \%$ the variation of strength with porosity (Fig.4) seems again higher than that of the Young's modulus (Fig. 2). At this porosity level in ceramic bodies some pore connectivity effect could be expected and be responsible of the further decrease of strength, e.g. for BB08 and 3YSZ etch samples. It is noteworthy that the failure strain of Ni-3YSZ (2G-DTU) is higher than that in the pure 3YSZ samples. This improvement in failure strain is ascribed to the ductile behaviour of the Ni metal in the composite, which could add a crack branching effect to transformation toughening, increasing the incremental toughness in the R-curve. This is in agreement with recent results by De Wei et al, [58] and previous findings by Deng et al. [14]. (R-curve behaviour for the composite Ni-3YSZ was however not investigated).

The peak in the failure strain in the BB09 sample could be due to the use of 3YSZ fibres in the original slurry. We speculate that the use of fibers (10wt\% of the total 3YSZ) decrease both strength and modulus due interactions between the fibers and pores. Since the fibers in the tape casting composites have a random distribution, the interaction between the fibers and pores during the sintering process, may lead to voids, cracks and poor bonding between the fibers and the matrix. The effect of this voids might be more evident in the modulus, since the strength is favoured by the R-curve behaviour present in this material. A lower strength but a higher resistance to strains from thermal gradients is expected in this material, since the ability of materials to withstand thermal stresses is directly proportional to the strain at failure [17].

\section{F. Subcritical crack growth}

For the most porous samples (e.g. BB08) R-curve behaviour was not observed. Instead SCCG was detected. However, in the BB10 samples, the U-shape of the of the crack growth velocity versus K curve could reflect an influence of R-curve behaviour on the subcritical crack growth. Such u-curve behaviour has been explained in detail in ref. [63]. The reason for the behaviour here might be a beneficial effect of the precalcined 3YSZ used in the BB10 samples, which can induce a transformation toughening effect, despite the high level of porosity. Furthermore, the presence of calcined 3YSZ grains could give rise to crack deflection during crack propagation, leading to a further increase in toughness and strength. 
In fact, BB10, despite having similar porosity to that of BB08, shows a higher value of $K_{I C}^{f}$ and consequently higher tensile strength.

Currently, there is a lack of analytical models for the experimentally obtained family of curves representing the variation of crack velocity in the subcritical region vs. applied stress intensity factor $\left(K_{I C}^{i}\right)$ as function of porosity. The SCCG behavior of YSZ has been modelled by Atkinson and Selcuk by a power-law function [10]:

$\frac{d a}{d t}=A\left(K_{I}\right)^{n}$

where $A$ and $n$ are fitting constants. For their data, corresponding to 8YSZ electrolyte, they obtained $n \sim 20$. Kumar and Sørensen [11] also fit their SCCG data for 8YSZ with the same function obtaining $n \sim 50$. In the case of the NiO-3YSZ data reported in ref. [12] (15\% of porosity), an $n$ value of $\sim 28$ is reported. Finally, for the porous 3YSZ support (54\% porosity) here investigated (BB08), the $n$ value obtained by fitting the experimental data plotted in Fig. 6 in logarithmic scale is approximately 3. From this, even if some data are for 8YSZ and other for 3YSZ, it is clear that $n$ decreases with increasing porosity. A low $n$ indicates that the material is susceptible to slow crack growth over a broad $K_{I}$ range and a higher value conversely indicates susceptibility only over a narrow range. From the data in Fig. 6 it is also clear that at the same applied stress intensity factor, the velocity of SCCG of BB08 is higher than NiO-3YSZ. This is indicated by constant $A$ of eq. 31: 2.63E-05 m²/(MPa s) for the 8YSZ reported in ref. [10];2.76E-10 $\mathrm{m}^{1 / 2} /$ (MPa s) for the NiO-3YSZ data reported in ref. [12] and $0.6 \mathrm{~m}^{1 / 2} /$ (MPa s) for the porous BB08 samples tested here. Thus the velocity of crack propagation increases with porosity.

The disappearance of R-curve behaviour for the most porous samples could indicate that the autocatalytic process is time dependent as previously observed in the literature [64] but also dependent on the porosity/stiffness of the backbones. For the denser samples (BB05, BB06) the transformation occurs more or less instantaneously and R-curve behaviour is observed. For the more porous samples (BB08 and BB10) the transformation in the wake of the crack tip is slower due to the fewer twinning nucleation points (less transformable material) and the lower loading rate (tortuous path). Thus, enhancing the stress intensity factor induces a more rapid and more widespread autocatalytic process into the porous network, whereas a lower stress intensity factor allows the stresses to relax and less spreading to occur, which leads to the SCCG. 
SCCG also occurs in the NiO-YSZ samples studied by Goutianos et. al. [12].Here the amount of YSZ is approximately the same, as a porosity of $\mathrm{P}=15 \%$ corresponds to a $3 \mathrm{YSZ}$ density of $40 \%$. Also in this study no R-curve behaviour was observed. The NiO network could assist propagating stresses, but would not be active in any autocatalytic process. This indicates that it is rather the amount of transformable material than the stiffness of the material, which determines the shift to the SCCG regime.

\section{Conclusions}

Several porous 3YSZ backbone structures were fabricated with porosities (46-54\%) suitable for subsequent infiltration of an electrocatalyst. The measured mechanical properties of these highly porous 3YSZ supports were compared with available literature data for NiO-3YSZ, Ni-3YSZ and 8YSZ materials For $\sim 50 \%$ porosity the porous backbones had a Weibull strength of $\sim 149 \mathrm{MPa}\left(\mathrm{V}_{\text {eff }}=1 \mathrm{~mm}^{3}\right)$ (Table II). New semi-empirical models building on a strength-porosity correlation (Eq. 28-30) that takes into account both the diminution in strength due to the decrease of transformation toughening and the decrease given by the Young's modulus are presented.

The influence of zirconia fibres and precalcined 3YSZ on the mechanical properties of porous 3YSZ anode supports was also investigated. The use of YSZ fibres increases the required failure strain but on the other hand it lowers the mechanical strength, while precalcined 3YSZ powder increase slightly the strength and the fracture toughness without affecting the value of the strain at failure. R-curve behaviour was observed and modelled for dense 3YSZ samples in samples with $13 \%$ and $\sim 46 \%$ of porosity. Hence, even in highly porous samples mechanical implications of a transformation toughening are observed. However, for the high porosities $>46 \%$ the toughening is not very effective in enhancing strength. From analysis of the R-curves it was found that even if the increase in porosity yields lower strength it has some beneficial effect on reliability via an increase in the flaw tolerance. However, for the structures with the highest porosities, exceeding 49\% (BB10, 49\%) (BB08, 54\%) R-curve behaviour is replaced by subcritical crack growth behaviour. The crack growth rate of subcritical crack growth was also measured and modelled by Atkinson's empirical power-law, showing an increase in the rate with increasing porosity. From these results, we concluded that the porous 3YSZ support enhanced with precalcined 3YSZ should resist better the room temperature mechanical loading during handling and stack formation (higher strength), while the support enriched with YSZ fibres should withstand better the stresses arising from thermal loading on service (higher failure strain). Further investigations are 
being carried out to develop a constitutive model for the assessment of the critical porosity value from which transformation toughening effect disappears. All in all, the data on the mechanical properties of porous 3YSZ supports compiled in this work suggests that indeed from a mechanical perspective impregnated 3YSZ supports can be an alternative to the conventional NiO-3YSZ anodes, due to their higher resistance to creep and thermal stresses.

\section{Acknowledgment}

The work was financially supported by the DTU Department of Energy Conversion and Storage. The authors gratefully acknowledge Marianne Nielsen and Henrik Paulsen (DTU Energy Conversion) for technical assistance in sample fabrication, and Troels Hoff, Jan Sjølin and Erik Vogeley (Department of Wind Energy) for technical help with the mechanical tests. Bent F Sørensen is also gratefully acknowledge for his generous advices on the fracture toughness measurements.

\section{References}

[1] N.M. Minh, T. Takahashi, Science and Technology of Ceramic Fuel Cells, in: Sci. Technol. Ceram. Fuel Cells, 1995: pp. 1-14.

[2] R. Chiba, T. Ishii, F. Yoshimura, Temperature dependence of ionic conductivity in (1 - x)ZrO2-(xy)Sc2O3-yYb2O3 electrolyte material, Solid State Ionics. 91 (1996) 249-256. doi:10.1016/S01672738(96)83026-8.

[3] J. Chevalier, C. Olagnon, G. Fantozzi, Subcritical Crack Propagation in 3Y-TZP Ceramics: Static and Cyclic Fatigue, J. Am. Ceram. Soc. 82 (2004) 3129-3138. doi:10.1111/j.11512916.1999.tb02213.x.

[4] T. Klemens $\varnothing$, D. Boccaccini, K. Brodersen, H.L. Frandsen, P. V. Hendriksen, Development of a novel ceramic support layer for planar solid oxide cells, Fuel Cells. 14 (2014) 153-161. doi:10.1002/fuce.201300121.

[5] T. Klemens $\varnothing$, K. Thydén, M. Chen, H.-J. Wang, Stability of Ni-yttria stabilized zirconia anodes based on Ni-impregnation, J. Power Sources. 195 (2010) 7295-7301. http://www.sciencedirect.com/science/article/pii/S0378775310009158 (accessed January 29, 2014).

[6] M. Radovic, E. Lara-Curzio, Mechanical properties of tape cast nickel-based anode materials for solid oxide fuel cells before and after reduction in hydrogen, Acta Mater. 52 (2004) 5747-5756. http://www.sciencedirect.com/science/article/pii/S1359645404005026 (accessed January 27, 2014).

[7] A. Selçuk, A. Atkinson, Elastic properties of ceramic oxides used in solid oxide fuel cells (SOFC), J. Eur. Ceram. Soc. 17 (1997) 1523-1532.

http://www.sciencedirect.com/science/article/pii/S0955221996002476 (accessed January 27, 
2014).

[8] H.L. Frandsen, T. Ramos, A. Faes, M. Pihlatie, K. Brodersen, Optimization of the strength of SOFC anode supports, J. Eur. Ceram. Soc. 32 (2012) 1041-1052.

http://www.sciencedirect.com/science/article/pii/S0955221911006078 (accessed January 27, 2014).

[9] A. Faes, H. Lund Frandsen, M. Pihlatie, A. Kaiser, D.R. Goldstein, Curvature and Strength of Ni-YSZ Solid Oxide Half-Cells After Redox Treatments, J. Fuel Cell Sci. Technol. 7 (2010) 51011. doi:10.1115/1.4001019.

[10] A. Atkinson, A. Selçuk, Mechanical behaviour of ceramic oxygen ion-conducting membranes, Solid State Ionics. 134 (2000) 59-66.

http://www.sciencedirect.com/science/article/pii/S0167273800007141 (accessed January 27, 2014).

[11] A.N. Kumar, B.F. Sørensen, Fracture Resistance and Stable Crack-Growth Behavior of 8-mol\%Yttria-Stabilized Zirconia, J. Am. Ceram. Soc. 83 (2000) 1199-1206.

[12] S. Goutianos, H.L. Frandsen, B.F. Sørensen, Fracture properties of nickel-based anodes for solid oxide fuel cells, J. Eur. Ceram. Soc. 30 (2010) 3173-3179.

http://www.sciencedirect.com/science/article/pii/S0955221910003468 (accessed January 28, 2014).

[13] A. Nakajo, J. Kuebler, A. Faes, U.F. Vogt, H.J. Schindler, L.-K. Chiang, S. Modena, J. Van herle, T. Hocker, Compilation of mechanical properties for the structural analysis of solid oxide fuel cell stacks. Constitutive materials of anode-supported cells, Ceram. Int. 38 (2012) 3907-3927. doi:10.1016/j.ceramint.2012.01.043.

[14] Z.-Y. Deng, J.-F. Yang, Y. Beppu, M. Ando, T. Ohji, Effect of Agglomeration on Mechanical Properties of Porous Zirconia Fabricated by Partial Sintering, J. Am. Ceram. Soc. 85 (2002) 19611965. doi:10.1111/j.1151-2916.2002.tb00388.x.

[15] W. Pabst, E. Gregorová, G. Tichá, Elasticity of porous ceramics-A critical study of modulus-porosity relations, J. Eur. Ceram. Soc. 26 (2006) 1085-1097. http://www.sciencedirect.com/science/article/pii/S0955221905000981 (accessed January 29, 2014).

[16] M. Radovic, E. Lara-Curzio, L. Riester, Comparison of different experimental techniques for determination of elastic properties of solids, Mater. Sci. Eng. A. 368 (2004) 56-70.

http://www.sciencedirect.com/science/article/pii/S0921509303009766 (accessed January 29, 2014).

[17] D.P.H. Hasselman, Unified Theory of Thermal Shock Fracture Initiation and Crack Propagation in Brittle Ceramics, J. Am. Ceram. Soc. 52 (1969) 600-604. doi:10.1111/j.11512916.1969.tb15848.x.

[18] R.M. McMeeking, A.G. Evans, Mechanics of Transformation-Toughening in Brittle Materials, J. Am. Ceram. Soc. 65 (1982) 242-246. doi:10.1111/j.1151-2916.1982.tb10426.x.

[19] C.-S. Yu, D.K. Shetty, Transformation yielding, plasticity and crack-growth-resistance (R-curve) behaviour of CeO2-TZP, J. Mater. Sci. 25 (1990) 2025-2035. doi:10.1007/BF01045759.

[20] K.E. Perry, G.B. May, J.S. Epstein, H. Okada, S.N. Atluri, Experimental R-curve behavior in partially stabilized zirconia using moiré interferometry, Acta Metall. Mater. 41 (1993) 361-368. http://www.sciencedirect.com/science/article/pii/0956715193900662 (accessed January 28, 
2014).

[21] C.L. Hom, R.M. McMeeking, Numerical results for transformation toughening in ceramics, Int. J. Solids Struct. 26 (1990) 1211-1223.

http://www.sciencedirect.com/science/article/pii/0020768390900573 (accessed January 28, 2014).

[22] D.B. Marshall, Strength Characteristics of Transformation-Toughened Zirconia, J. Am. Ceram. Soc. 69 (1986) 173-180. doi:10.1111/j.1151-2916.1986.tb07402.x.

[23] K. Kendall, N.M. Alford, S.R. Tan, J.D. Birchall, Influence of toughness on Weibull modulus of ceramic bending strength, J. Mater. Res. 1 (1986) 120-123.

http://journals.cambridge.org/abstract_S0884291400096461 (accessed October 19, 2014).

[24] R.H.J. Hannink, P.M. Kelly, B.C. Muddle, Transformation Toughening in Zirconia-Containing Ceramics, J. Am. Ceram. Soc. 83 (2004) 461-487. doi:10.1111/j.1151-2916.2000.tb01221.x.

[25] B. Budiansky, J.W. Hutchinson, J.C. Lambropoulos, Continuum theory of dilatant transformation toughening in ceramics, Int. J. Solids Struct. 19 (1983) 337-355. http://www.sciencedirect.com/science/article/pii/0020768383900318 (accessed January 28, 2014).

[26] B. Lawn, Fracture of Brittle Solids, 2nd Editio, Cambridge University Press, 1993.

[27] S.M. Wiederhorn, Crack Propagation in Soda-Lime Glass, J. Am. Ceram. Soc. 1966 (1967).

[28] S.W. Freiman, D.R. Mulville, P.W. Mast, Crack propagation studies in brittle materials, J. Mater. Sci. 8 (1973) 1527-1533. doi:10.1007/BF00754886.

[29] T.A. Michalske, B.C. Bunker, Slow fracture model based on strained silicate structures, J. Appl. Phys. 56 (1984) 2686. doi:10.1063/1.333789.

[30] A. Shyam, E. Lara-Curzio, The double-torsion testing technique for determination of fracture toughness and slow crack growth behavior of materials: A review, J. Mater. Sci. 41 (2006) 40934104. doi:10.1007/s10853-005-5553-0.

[31] H.L. Frandsen, The small displacement elastic solution to the ball-on-ring testing method, Mech. Mater. 55 (2012) 33-40. http://www.sciencedirect.com/science/article/pii/\$0167663612001408 (accessed January 29, 2014).

[32] R.M. Kirstein, A.F.; Woolley, Symmetrical bending of thin circular elastic plates on equally spaced point supports, J. Res. Nat. Bur. Stand. Sec. C Eng. 71C (1967) 1. https://archive.org/details/jresv71Cn1p1 (accessed May 23, 2014).

[33] W. Weibull, A statistical distribution function of wide applicability, J. Appl. Mech. 18 (1951) 293297. http://web.cecs.pdx.edu/ cgshirl/Documents/Weibull-ASME-Paper-1951.pdf.

[34] H.L. Frandsen, Weibull statistics effective area and volume in the ball-on-ring testing method, Mech. Mater. 73 (2014) 28-37. doi:10.1016/j.mechmat.2013.10.010.

[35] A. Winnubst, K. Keizer, A. Burggraaf, Mechanical properties and fracture behaviour of ZrO2-Y2O3 ceramics, J. Mater. Sci. 18 (1983) 1958-1966.

http://link.springer.com/article/10.1007/BF00554988 (accessed May 22, 2014).

[36] V.S. Ramakrishnan, N.; Arunachalam, Effective elastic moduli of porous solids, J. Mater. Sci. 25 (1990) 3930-3937.

[37] R.M. Spriggs, Expression for Effect of Porosity on Elastic Modulus of Polycrystalline Refractory 
Materials, Particularly Aluminum Oxide, J. Am. Ceram. Soc. 44 (1961) 628-629.

doi:10.1111/j.1151-2916.1961.tb11671.x.

[38] R.W. Rice, Evaluating Porosity Parameters for Porosity-Property Relations, J. Am. Ceram. Soc. 76 (1993) 1801-1808. doi:10.1111/j.1151-2916.1993.tb06650.x.

[39] N. Ramakrishnan, V.S. Arunachalam, Effective Elastic Moduli of Porous Ceramic Materials, J. Am. Ceram. Soc. 76 (1993) 2745-2752. doi:10.1111/j.1151-2916.1993.tb04011.x.

[40] Z. Hashin, The Elastic Moduli of Heterogeneous Materials, J. Appl. Mech. 29 (1962) 143. doi:10.1115/1.3636446.

[41] D.N. Boccaccini, A.R. Boccaccini, Dependence of Ultrasonic Velocity on Porosity and Pore Shape in Sintered Materials, J. Nondestruct. Eval. 16 (1997) 187-192. doi:10.1023/A:1021891813782.

[42] A.R. Boccaccini, G. Ondracek, The Quantitative Microstructure-Property Correlations of Composite and Porous Materials: An Engineering Tool for Designing New Materials, in: R. Pyrz (Ed.), IUTAM Symp. Microstruct. Interact. Compos. Mater., Springer Netherlands, Dordrecht, 1995: p. pp 27-38. doi:10.1007/978-94-011-0059-5.

[43] C.A. Andersson, Derivation of the Exponential Relation for the Effect of Ellipsoidal Porosity on Elastic Modulus, J. Am. Ceram. Soc. 79 (1996) 2181-2184. doi:10.1111/j.11512916.1996.tb08955.x.

[44] G. Bao, S. Ho, Z. Suo, B. Fan, The role of material orthotropy in fracture specimens for composites, Int. J. Solids Struct. 29 (1992) 1105-1116. doi:10.1016/0020-7683(92)90138-J.

[45] J.W. Hutchinson, Z. Suo, Mixed Mode Cracking in Layered Materials, Adv. Appl. Mech. 29 (1991) 63-191. doi:10.1016/S0065-2156(08)70164-9.

[46] P.M. Kelly, L.R. Francis Rose, The martensitic transformation in ceramics - its role in transformation toughening, Prog. Mater. Sci. 47 (2002) 463-557.

http://www.sciencedirect.com/science/article/pii/S0079642500000050 (accessed December 2, 2013).

[47] A.G. Evans, Toughening Mechanisms in Zirconia Alloys, in: H.A.H. Claussen, N., Riihle. M. (Ed.), Adv. Ceram., American Ceramic Society. Columbus, OH, 1984: pp. 193-212.

[48] N. Ramachandran, D.K. Shetty, Prediction of indentation-load dependence of fracture strengths from R-curves of toughened ceramics, J. Mater. Sci. 28 (1993) 6120-6126. doi:10.1007/BF00365032.

[49] J. Gong, Z. Guan, Strength characteristics of toughened ceramics containing contact-induced small surface cracks, Mater. Sci. Eng. A. 344 (2003) 132-139. doi:10.1016/S0921-5093(02)003969.

[50] R.F. Cook, D.R. Clarke, Fracture stability, R-curves and strength variability, Acta Metall. 36 (1988) 555-562. doi:10.1016/0001-6160(88)90088-0.

[51] T. Fett, D. Munz, Influence of narrow starter notches on the initial crack growth resistance curve of ceramics, Arch. Appl. Mech. 76 (2006) 667-679. doi:10.1007/s00419-006-0055-3.

[52] A.H. Heuer, Transformation Toughening in ZrO2-Containing Ceramics, J. Am. Ceram. Soc. 70 (1987) 689-698. doi:10.1111/j.1151-2916.1987.tb04865.x.

[53] B.F. Sørensen, P. Brethe, P. Skov-Hansen, Controlled crack growth in ceramics: The DCB specimen loaded with pure moments, J. Eur. Ceram. Soc. 16 (1996) 1021-1025. doi:10.1016/09552219(96)00021-0. 
[54] G. Roebben, B. Bollen, A. Brebels, J. Van Humbeeck, O. Van der Biest, Impulse excitation apparatus to measure resonant frequencies, elastic moduli, and internal friction at room and high temperature, Rev. Sci. Instrum. 68 (1997) 4511. doi:10.1063/1.1148422.

[55] M. Pihlatie, A. Kaiser, M. Mogensen, Mechanical properties of NiO/Ni-YSZ composites depending on temperature, porosity and redox cycling, J. Eur. Ceram. Soc. 29 (2009) 1657-1664. doi:10.1016/j.jeurceramsoc.2008.10.017.

[56] B.F. Sørensen, A. Horsewell, O. Jørgensen, A.N. Kumar, P. Engbaek, Fracture Resistance Measurement Method for in situ Observation of Crack Mechanisms, J. Am. Ceram. Soc. 81 (2005) 661-669. doi:10.1111/j.1151-2916.1998.tb02387.x.

[57] A. Freudenthal, Statistical approach to brittle fracture, in: H. Liebowitz (Ed.), Fract. Adv. Treatise Vol.II, Academic Press, San Diego, CA, 1968: pp. 591-619.

[58] D.-W. Ni, B. Charlas, K. Kwok, T.T. Molla, P.V. Hendriksen, H.L. Frandsen, Influence of temperature and atmosphere on the strength and elastic modulus of solid oxide fuel cell anode supports, J. Power Sources. 311 (2016) 1-12. doi:10.1016/j.jpowsour.2016.02.027.

[59] R.H.J. Hannink, M. V. Swain, Progress in transformation toughening of ceramics, Annu. Rev. Mater. Sci. 24 (1994) 359-408.

[60] A.G. Evans, Perspective on the Development of High-Toughness Ceramics, J. Am. Ceram. Soc. 73 (1990) 187-206. doi:10.1111/j.1151-2916.1990.tb06493.x.

[61] D.K. Shetty, J.-S. Wang, Crack Stability and Strength Distribution of Ceramics That Exhibit Rising Crack-Growth-Resistance (R-Curve) Behavior, J. Am. Ceram. Soc. 72 (1989) 1158-1162. doi:10.1111/j.1151-2916.1989.tb09700.x.

[62] A.H. Heuer, M.J. Readey, R. Steinbrech, Resistance curve behavior of supertough MgO-partiallystabilized ZrO2, Mater. Sci. Eng. A. 105-106 (1988) 83-89. doi:10.1016/0025-5416(88)90483-1.

[63] D. Munz, T. Fett, Influence of R-curve behaviour on Subcritical Crack Growth, in: D. Munz, T. Fett (Eds.), Ceram. Mech. Prop. Fail. Behav. Mater. Sel., Springer, 1999: p. 96. http://books.google.com/books?id=6I9YTABxdYMC\&pgis=1 (accessed February 5, 2014).

[64] D.M. Stump, Autocatalysis: The self-induced growth of martensitic phase transformations in ceramics, Acta Metall. Mater. 42 (1994) 3027-3033. doi:10.1016/0956-7151(94)90399-9. 